Portland State University

PDXScholar

Civil and Environmental Engineering Master's

Project Reports

$12-16-2019$

\title{
Evaluation of a Novel Remote Displacement Sensor Prototype Using Video and Laser-Based Technology for Civil Infrastructure Applications
}

Nicholas J. Brown

Portland State University

Follow this and additional works at: https://pdxscholar.library.pdx.edu/cengin_gradprojects

Part of the Structural Engineering Commons

Let us know how access to this document benefits you.

\section{Recommended Citation}

Brown, Nicholas J., "Evaluation of a Novel Remote Displacement Sensor Prototype Using Video and LaserBased Technology for Civil Infrastructure Applications" (2019). Civil and Environmental Engineering Master's Project Reports. 49.

https://doi.org/10.15760/CCEMP.48

This Project is brought to you for free and open access. It has been accepted for inclusion in Civil and Environmental Engineering Master's Project Reports by an authorized administrator of PDXScholar. Please contact us if we can make this document more accessible: pdxscholar@pdx.edu. 


\section{EVALUATION OF A NOVEL REMOTE DISPLACEMENT SENSOR PROTOTYPE USING VIDEO AND LASER-BASED TECHNOLOGY FOR CIVIL INFRASTRUCTURE APPLICATIONS}

\section{BY}

\section{NICHOLAS BROWN}

\section{A research project report submitted in partial fulfillment of the requirement for the degree of}

\section{MASTER OF SCIENCE \\ IN \\ CIVIL AND ENVIRONMENTAL ENGINEERING}

Project Advisor:

Thomas Schumacher

Portland State University

(C)2019 


\section{ACKNOWLEDGMENTS}

The author would like to extend his thanks to Portland State University for the financial support and use of its facilities and also to the University of Burgos for allowing the use of the patent shown in this paper. 


\begin{abstract}
Deflection measurements on structures, especially with regards to long-term monitoring, continues to be a challenge with current sensor technologies. Material degradation and changes in the mechanical properties due to aging (for example, creep and shrinkage in concrete bridges) directly impact the deflections exhibited by a structure. In this article we introduce and discuss the evaluation of a novel laser and video-based displacement sensor prototype to monitor displacements and rotations in structures remotely. The sensor is both inexpensive, using off-the shelf components, but also accurate and practical for situations that do not allow the use of conventional displacement sensors, which require a reference base. In contrast to other imagebased approaches such as digital image correlation or Eulerian-based video sensors, our camerabased sensor is located at the measurement location on the structure. The sensor was evaluated using laboratory tests to determine the practicality, accuracy, and sensitivity to lighting conditions. The accuracy of the sensor was found to be approximately $+/-0.9 \mathrm{~mm}(95 \%$ confidence limits) for a $30.5 \mathrm{~m}$ (100 ft) measurement distance. Finally, we applied and evaluated the sensor under real-world conditions on a prestressed concrete bridge under different loading conditions as well as on a five-story steel moment-frame building under ambient conditions. Essential for field applications, the results demonstrate the prototype offers an inexpensive yet practical and accurate solution for monitoring displacements and rotations remotely.
\end{abstract}




\section{TABLE OF CONTENTS}

1.0 INTRODUCTION .......................................................................................................................1

2.0 SENSOR DESIGN...........................................................................................................

2.1 COMPONENTS AND EQUIPMENT ..........................................................................................................

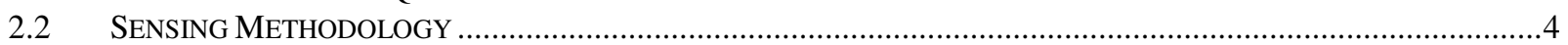

2.2.1 Distortion Correction …………………………………………………………………………………5

2.2.2 Centroid Detection Technique ......................................................................................................... 7

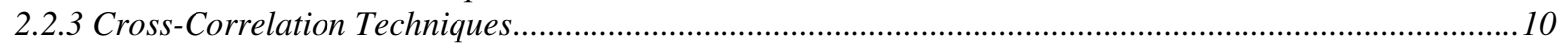

3.0 TEST SETUPS AND PROCEDURES..........................................................................................12

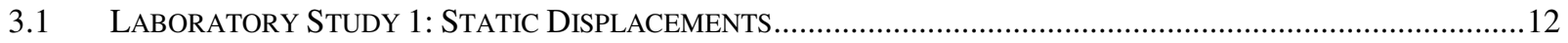

3.2 LABORATORY STUDY 2: EFFECT OF LIGHTING CONDITIONS ..............................................................13

3.3 FIELD STUdy 1: MONITORING OF A FIVE-STORY BUILDING UNDER AMBIENT LOADING CONDITIONS ..........14

3.4 FIELD STUDY 2: MONITORING OF A BRIDGE UNDER VARIOUS LOADING CONDITIONS ..............................16

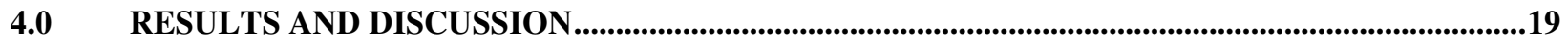

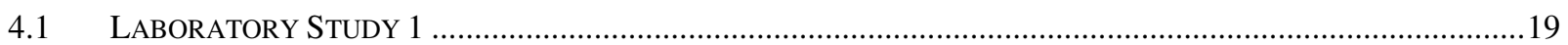

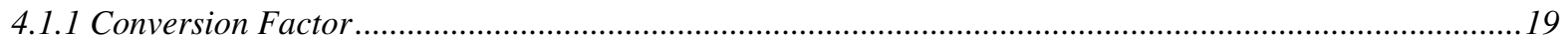

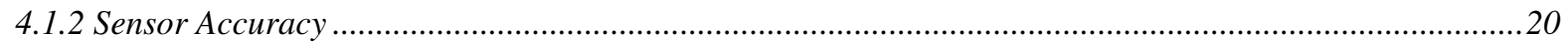

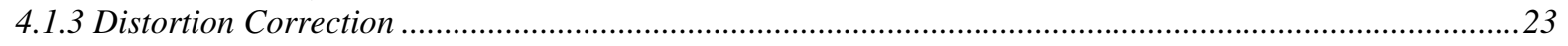

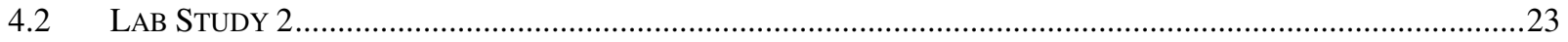

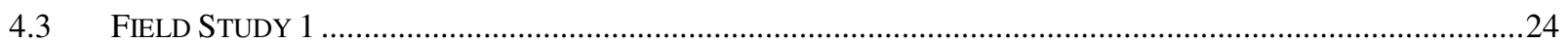

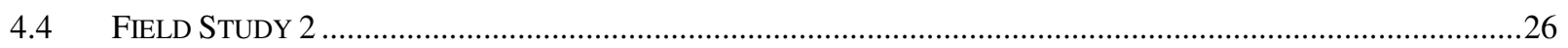

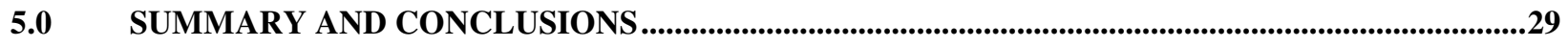

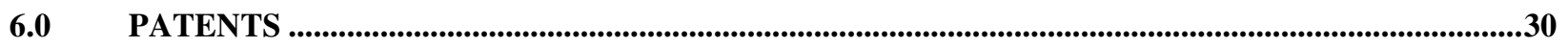

7.0 REFERENCES .........................................................................................................................................31 


\section{LIST OF FIGURES}

FIG. 1 ILLUSTRATION OF THE PROTOTYPE DISPLACEMENT SENSOR IN A LABORATORY TEST SETUP: (A) FIXED AND (B) MOVABLE PART...

FIG. 2 SENSING METHODOLOGY (CORRESPONDING SECTION NUMBERS GIVEN IN PARENTHESES) .5

FIG. 3 IMAGE TAKEN SHOWING CALIBRATION CHECKERBOARD: (A) BEFORE AND (B) AFTER DISTORTION CORRECTION PROCESSING ……...............................................................

FIG. 4 INTERMEDIATE PROCESSING STEP SHOWING HISTOGRAMS OF THE (A) RED, (B) GREEN, AND

(C) BLUE COLOR BANDS FROM A SINGLE IMAGE

\section{.8}

FIG. 5 INTERMEDIATE PROCESSING STEP SHOWING (A) ORIGINAL IMAGE PRIOR TO PROCESSING,

(B) LASER DOT MASK RESULTING FROM COLOR THRESHOLDING PROCEDURE, AND (C)

ORIGINAL IMAGE WITH LASER CENTROID LOCATIONS IDENTIFIED .....

FIG. 6 PHOTO OF SENSOR PROTOTYPE: (A) FIXED AND (B) MOVABLE PART OF THE SENSOR USED IN LABORATORY STUDY 1

FIG. 7 SAMPLE IMAGES TAKEN UNDER (A) INDOOR FLUORESCENT, (B) DIRECT SUNLIGHT, (C) PARTIAL SHADE, AND (D) COMPLETE DARKNESS LIGHTING CONDITIONS

FIG. 8 PHOTOS SHOWING SENSOR CONFIGURATION FOR FIELD STUDY 1: (A) VIEW FROM TOP TO BOTTOM OF STAIRCASE SHOWING BOTH SENSOR PARTS AND (B) MOVABLE PART OF THE SENSOR WITH LASER DOTS.

FIG. 9 ELEVATION VIEW OF PEDESTRIAN BRIDGE AT REED COLLEGE IN PORTLAND, OREGON .......17

FIG. 10 CORRELATION PLOTS FOR THE SINGLE-STEP DFT TECHNIQUE FOR ALL MEASUREMENT DISTANCES WITH CURVE FIT FUNCTIONS: (A) $3.05 \mathrm{M}$ (10 FT), (B) $15.2 \mathrm{M}$ (50 FT), (C) $30.5 \mathrm{M}$ (100 FT). GREEN DASHED LINES REPRESENT 95\% PREDICTION LIMITS...

FIG. 11 SENSOR ACCURACY VERSUS MEASUREMENT DISTANCE FOR CROSS-CORRELATION, SINGLE-STEP DFT, AND CENTROID TECHNIQUES

FIG. 12 AVERAGE PROCESSING TIME VERSUS PROCESSING TECHNIQUE.

FIG. 12 SENSOR ACCURACY FOR PRE-DISTORTION AND POST-DISTORTION CORRECTION PROCESSING VERSUS MEASUREMENT DISTANCE (CENTROID TECHNIQUE)

FIG. 13 DISPLACEMENT MEASUREMENTS TAKEN IN THE X AND Y-DIRECTIONS FOR FIELD STUDY 1 USING THE SINGLE-STEP DFT TECHNIQUE: (A) LASERS IN THE X-DIRECTION, (B) LASERS IN THE Y-DIRECTION .24

FIG. 14 ROTATION MEASUREMENTS COMPUTED FROM STUDY 1 USING THE SINGLE-STEP DFT TECHNIQUE

FIG. 15 FAST FOURIER TRANSFORM RESULTS FROM THE FIRST TEST IN FIELD EXPERIMENT \#1: (A) X-COORDINATE, (B) Y-COORDINATE.

FIG. 16 (A) DISPLACEMENT MEASUREMENTS AND (B) FAST-FOURIER TRANSFORM IN THE YDIRECTION FOR LASER 1 DURING TEST 1 OF FIELD STUDY 2 USING THE SINGLE-STEP DFT TECHNIQUE AND (C) FAST FOURIER TRANSFORM RESULTS FROM ACCELEROMETER IN FIELD EXPERIMENT \#2 IN THE Z-DIRECTION 


\subsection{INTRODUCTION}

Historically, visual inspection has been the primary method of structural condition assessment. Visual degradation of materials, cracking, large displacements, etc. are visual cues for structural deficiencies in a structure. Unfortunately, these rely on the subjective judgement of the inspector, and require structural deficiencies to be severe enough to be seen with the naked eye (or assistive tools). With the rapid evolution of digital sensors over the last decade, alternative monitoring solutions have been researched and developed that seek to identify structural deficiencies continuously before they become extreme.

Deflection monitoring may be one of the most desired and crucial variables associated with structural health since it directly correlates with the serviceability of the structure [1]. Long-term effects such as creep, shrinkage, and prestressing losses in prestressed/post-tensioned structures directly impact deflection. The same observations can be made with regards to the effects of environmental processes on a structure (corrosion, carbonation, overall structural aging, etc.).

Although highly useful, long-term monitoring of deflections on structures has proven to be challenging due to the shortcomings of current measurement technologies [2]. In addition to the harsh environmental conditions often surrounding bridges and structures such as parking garages, the scale of the structure often makes such measurements more difficult. The currently available technologies to measure displacements such as linear variable differential transducers (LVDT) or potentiometers, GPS-based systems, accelerometers, laser distance meters, either require the sensor to be connected to a fixed reference, are of low resolution, are unable to measure slowly-varying displacements, or are expensive, respectively [3]. Thus, a cost-effective and reliable solution for monitoring long-term and potentially slowly-varying displacements on structures is needed.

More recently, video-based sensors have emerged as a potential alternative to fill this need. Advancements in video camera technology have resulted in widespread availability and lowered costs. In addition, video/image processing software has also become widely available. Although these sensor advancements are promising, there are drawbacks that need further development before it can be considered a reliable method of data collection. An initial problem with videobased sensors was with resolution. However, this has become less of an issue with the rapid 
advancement of camera technology over the last several years. With the increase in camera resolution comes the problem of file size and processing time. Large file sizes and long-term monitoring requirements necessitate the need for ways to store large amounts of data. In addition, video/image processing software must be capable of processing these large files quickly (common video cameras record video at 30-60 frames per second).

A significant amount of research has been published around the monitoring and evaluation of dynamic properties of structures using video-based sensors. Measurements have typically been carried out in short intervals of seconds or minutes. Results from these tests are typically compared to more traditional sensors such as accelerometers and LVDT [4 to 9]. Most videobased sensor solutions to date have placed the camera sensor at a fixed location off-structure [10 to 15]. The camera sensor is then pointed at an area of interest on the structure and data is collected. Our proposed sensing approach instead places the camera-based sensor on the structure at the measurement point of interest. A set of lasers is placed at a fixed location offstructure and then focused on a translucent panel attached to the camera sensor unit [16]. Any deflections experienced by the structure are then directly experienced by the camera sensor [17 and 18]. The movement of the sensor directly corresponds to movement of the laser dot location on the translucent panel (recorded direction of laser movement being in the opposite direction of the movement experienced by the sensor). An added benefit of this approach is that the sensor is less sensitive to rotational effects placed on the sensor itself.

In the following sections, the proposed laser and video-based displacement sensor is described in detail. Two laboratory-based studies aimed at quantifying accuracy, repeatability, and sensitivity to varying lighting conditions are presented and the results from two real-world applications are discussed. 


\subsection{SENSOR DESIGN}

\subsection{Components and Equipment}

Our proposed laser and video-based displacement sensor is comprised of two main components: a fixed part and a movable part. Figure 1 provides a general overview of the components. The fixed part (Figure 1(A)) is placed at an immovable location where it remains fixed for the entire duration of planned monitoring. It is comprised of two laser emitters secured to a fixed support. For this research, two inexpensive XY lasers were utilized that emit green light, producing two dots when focused on the translucent panel of the movable part of the sensor.

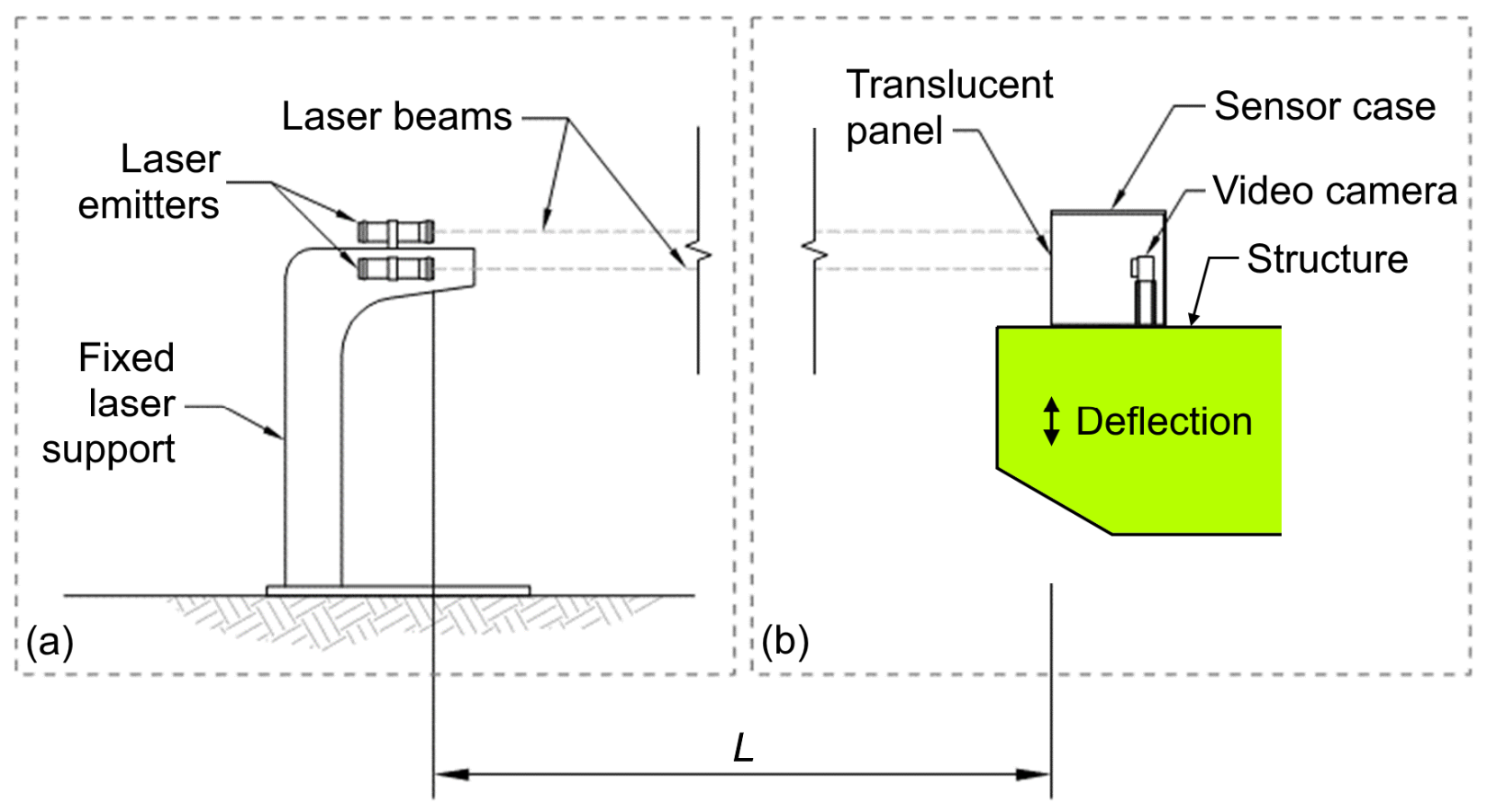

FIG. 1 ILLUSTRATION OF THE PROTOTYPE DISPLACEMENT SENSOR IN A LABORATORY TEST SETUP: (A) FIXED AND (B) MOVABLE PART

The movable part of the sensor (Figure 1(B)) is comprised of three main elements: a translucent panel, a series of (8) red light-emitting diodes (LED), and a video camera. The translucent panel is made of medium-weight plain white paper stock, measuring $100 \mathrm{~mm}$ (4 in) (= width) by 150 $\mathrm{mm}$ (6 in) (= height). The panel was fastened securely to the sensor housing to ensure the panel 
remained planar and orthogonal to the video camera. The red LED diodes are located around the perimeter of the panel and used to provide a reference coordinate system for calculating displacement and rotation of the sensor during testing. The video camera used during this research was a GoPro Hero 3-Black Edition (GoPro, San Mateo, CA, USA). Image resolution used during single image data collection was 3000 x 4000 pixels and images were recorded in the RGB color space. Videos were recorded at 30 frames per second, with a resolution of 2,704 $\mathrm{x}$ 1,536 pixels in the RGB color space. The video camera was fixed to the inside of the sensor housing via a $3 \mathrm{D}$ printed housing bracket attached to the housing. The video camera location was

chosen so that the recorded image captured the entire translucent panel and as little area beyond the panel as possible, while remaining within the focal length requirements of the lens.

The focal length of the standard lens that comes with the GoPro Hero 3-Black is $15 \mathrm{~mm}(0.59$ in). The resulting image captured with this short focal length results in what is commonly referred to as a "fish eye effect". To minimize the distortion of this in-camera, a +10 magnification lens (Brand: Vivitar, Model: Series 1 Close-Up Macro Lens (Sakar International, Inc., Edison, NJ, USA)) was attached to the face of the camera.

\subsection{Sensing Methodology}

The overall goal of the research was to develop a sensing methodology for capturing static and dynamic displacements on structures. A successful methodology is both accurate and repeatable, while minimizing data processing times. Two data processing approaches were considered for this research: centroid detection with color thresholding of the green laser dots used as reference points and cross-correlation techniques, which maximize a function describing the displacements between an image with a known location and orientation in space and an image of unknown location and orientation. Figure 2 provides a flowchart of the processing steps for the sensing methodology evaluated in this paper. 


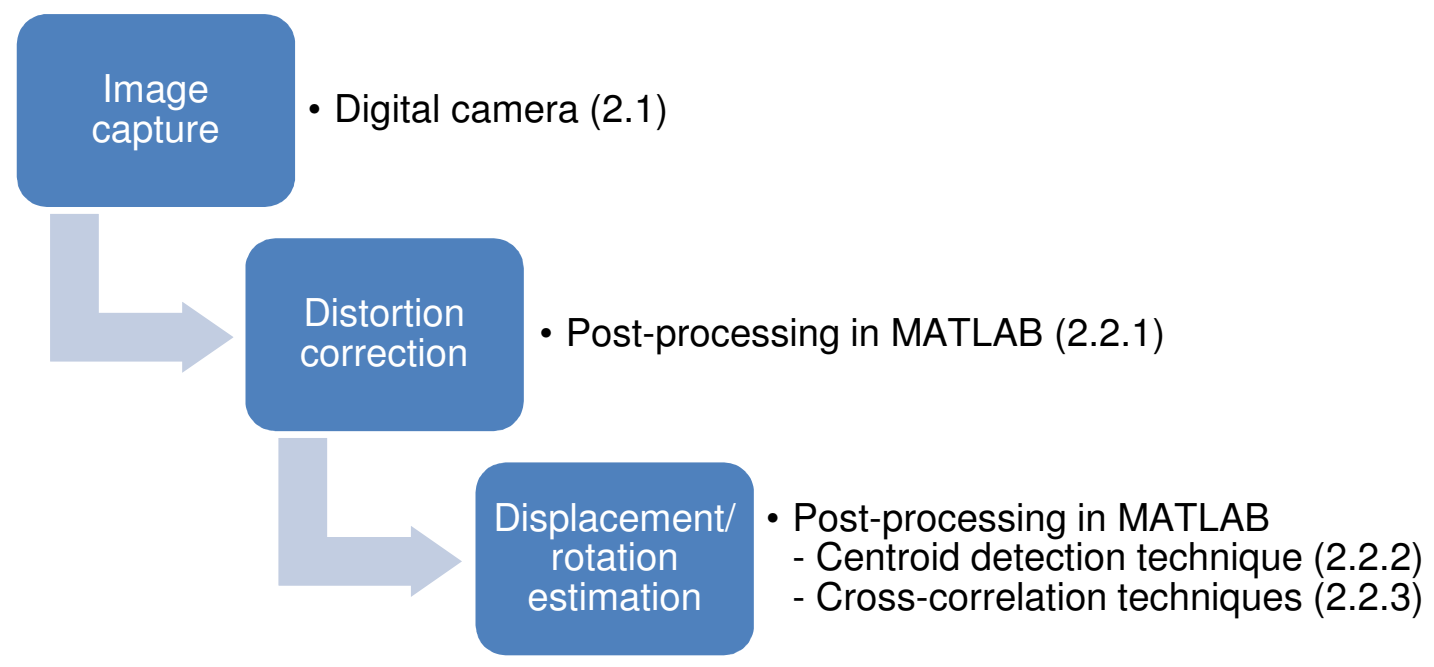

FIG. 2 SENSING METHODOLOGY (CORRESPONDING SECTION NUMBERS GIVEN IN PARENTHESES)

\subsubsection{Distortion Correction}

As mentioned in Section 2.1, a 10x magnification lens was attached to the face of the camera to minimize the "fish eye" effect of the small focal length of the camera. However, upon visual inspection of the captured images, it was apparent that not all the distortion caused by the small focal length of the camera had been removed. Additional post-processing of captured images to remove remaining distortion was performed prior to color thresholding procedures being applied [19 to 22]. Results were then compared to pre-distortion correction color thresholding results. The intent of the comparison was to determine the accuracy gain obtained by performing the distortion correction as well as the processing time required.

As part of MATLAB's Computer Vision Toolbox [23], several tools are available to assist in correcting image distortion. The following MATLAB function was utilized during this research:

$$
\text { [J,newOrigin }]=\text { undistortImage }(I, \text { cameraParams })
$$

where $J$ is the outputted undistorted image, newOrigin is a 2-element vector containing the output image origin, $I$ is the M-by-N-by-3 true-color input image, and cameraParams is the 
object used to store camera parameters. The camera parameters are determined using the estimatecameraparameters() function in MATLAB. This function returns an object containing estimates for the intrinsic and extrinsic parameters and distortion coefficients of a single camera. Several images from the camera in question are passed to the function which contain images of a calibration checkerboard. Along with the images, the real-world dimensions of the checkerboard squares are passed to the function. For the calibration used during this research, 11 images were used in the calibration process. Checkerboard squares were measured using a digital caliper and determined to be 18 by $18 \mathrm{~mm}$. Figure 3(A) shows one of the checkerboard images prior to processing. Figure 3(B) shows the same image after processing the image using the distortion correction parameters determined from the estimateCameraparameters () function.

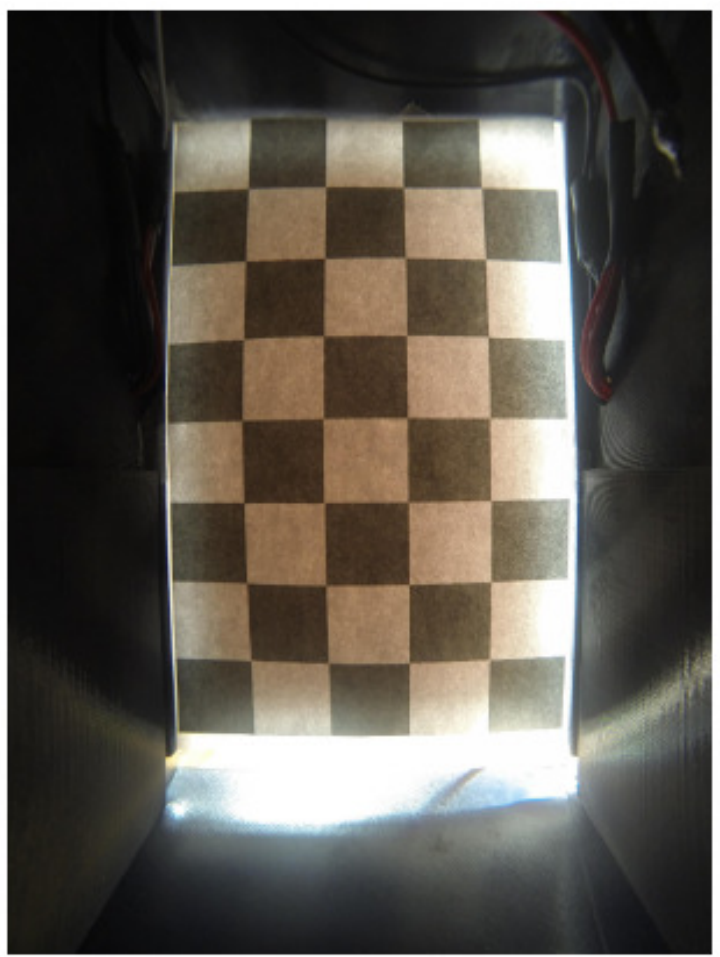

(A)

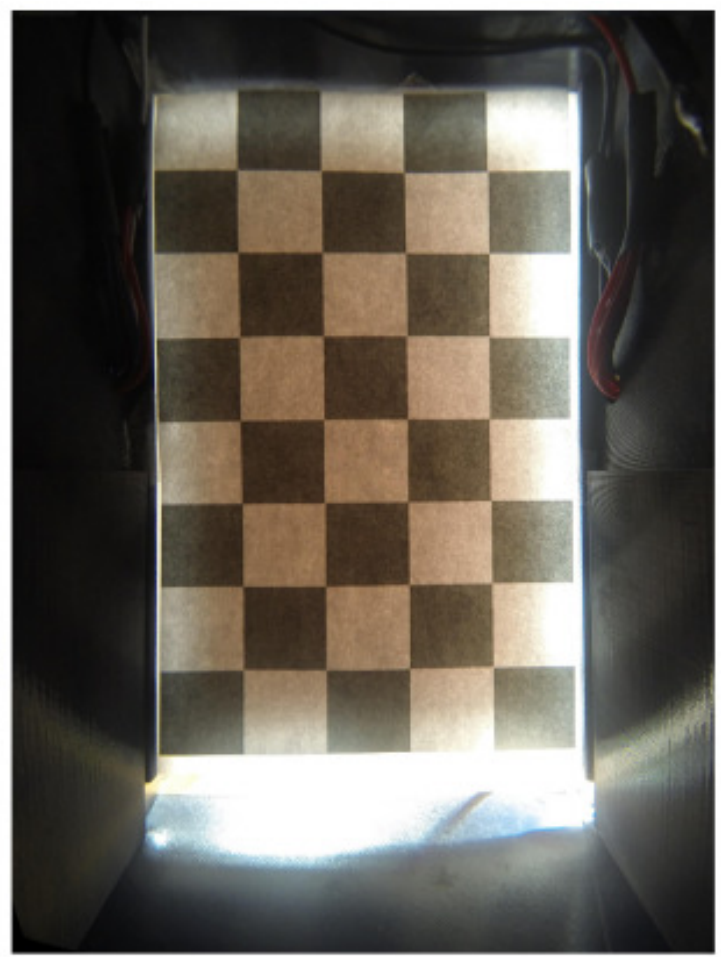

(B)

FIG. 3 IMAGE TAKEN SHOWING CALIBRATION CHECKERBOARD: (A) BEFORE AND (B) AFTER DISTORTION CORRECTION PROCESSING 


\subsubsection{Centroid Detection Technique}

The goal of the video/image centroid detection technique is two-fold. The first goal is to accurately and efficiently extract the centroid location of each green laser dot in a twodimensional space. The second, and equally as important, goal is to orient the centroid location extracted from each green laser dot with respect to some known "constant" location. In the case of this study, the red LEDs located around the perimeter of the sensor housing serve as the fixed location by which the green laser dots can be oriented (see Figure 5(A)). The laser emitters project a set of two green dots onto the translucent panel of the sensor.

The first challenge when approaching this problem is to correctly identify the centroid of each green dot within a single image/frame taken from the camera. This is accomplished using color thresholding procedures, e.g. following Huang and Wang [24]. Each image file contains information regarding the color and intensity of each pixel within the image. Color thresholding allows for the isolation of certain pixels within an image that fall within pre-defined color/intensity criteria. Certain colors, and certain color intensities, can then be isolated within an image.

Preliminary testing was performed to determine the thresholds necessary to repeatably identify only the green dot locations. A sample image was recorded which contained the two green laser dots that were desired to be isolated. The image data was broken into its three primary color bands: red, green, and blue. Histograms were generated for each of these color bands to determine the location of highest intensity within each color band. Threshold boundaries were selected to capture the most data within the green band, and the least data in the red and blue bands. Once isolated, additional pixel information within the image was removed to improve processing times.

Figure 4 displays an example of how the thresholding procedure works. The original image is displayed in the top left corner. The next three images across the top row display the isolated red, green, and blue color bands contained in the image. The grayscale images identify color intensity of that color band within the image. Lighter, white, pixels are indicative of higher color intensity at that location. The second row of images within the figure show histograms for each band. These identify the quantity of pixels at each intensity level. 

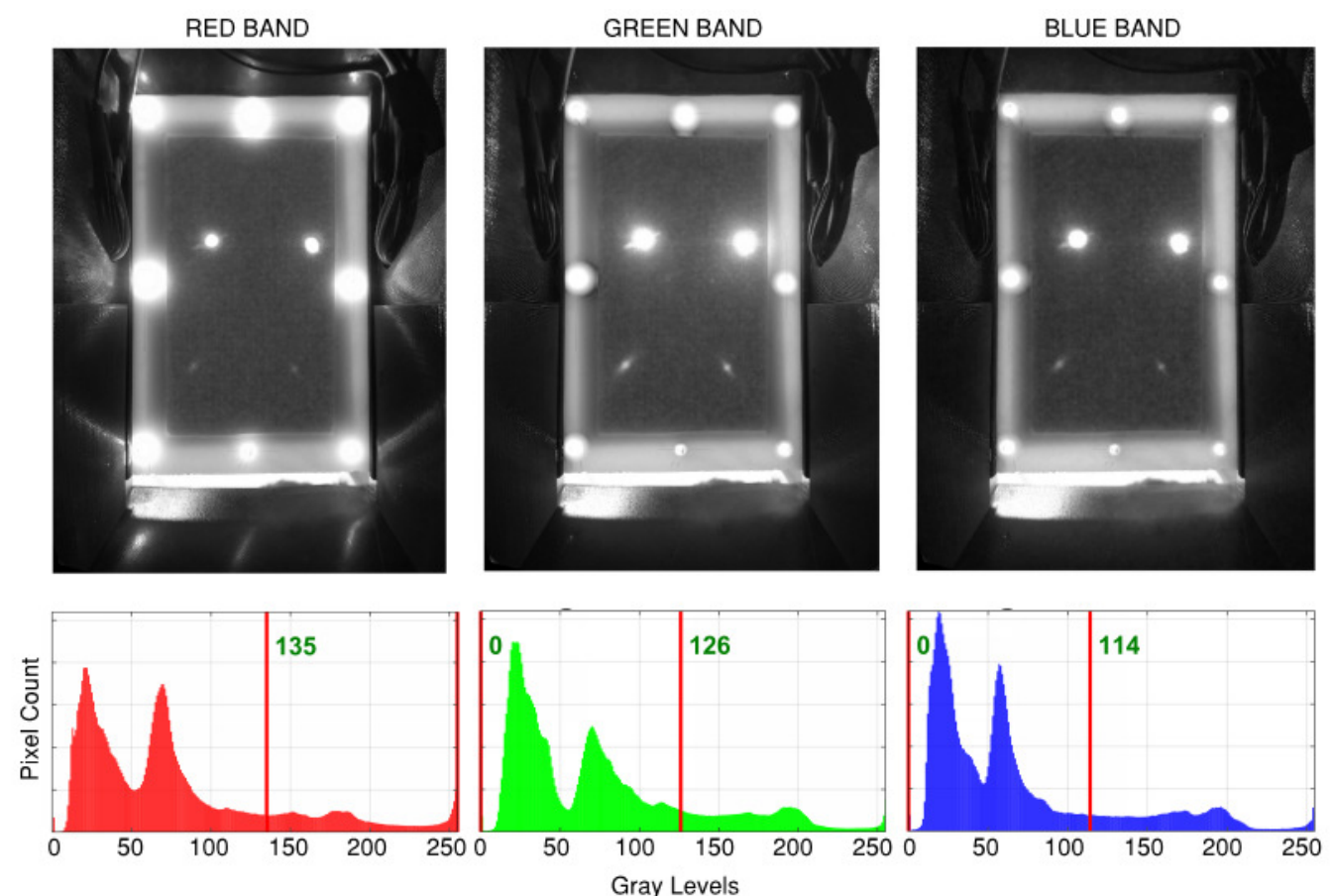

(A)

(B)

(C)

FIG. 4 INTERMEDIATE PROCESSING STEP SHOWING HISTOGRAMS OF THE (A) RED, (B) GREEN, AND (C) BLUE COLOR BANDS FROM A SINGLE IMAGE

Thresholds can now be placed on each color band to mask out the undesired color ranges from the image. In the case of this study, the green laser dots have higher intensities of color within each color band. Specifically, having the following boundaries for each color band allowed for reliable and repeatable green laser dot isolation:

Red color band threshold: 200-255

Green color band threshold: 200-255

Blue color band threshold: 200-255

Once the color band thresholds have been applied to the original image, the resulting image contains only the image data of interest. From here, a built in MATLAB function called regionprops () is used to extract several different properties from the image, such as areas of grouped pixels containing data, perimeter of those grouped pixels, and the centroid (center of mass) in 2-dimensional coordinates of the grouped pixels. 
Figure 5 shows the programmed MATLAB thresholding procedure and centroid detection technique at its intermediate steps. Figure 5(A) shows the undistorted image upon being imported into the program. Figure 5(B) shows the mask resulting from the applied color band thresholding. Figure 5(C) shows the original image with the locations of centroids calculated from regionprops ( ) superimposed in the respective locations.

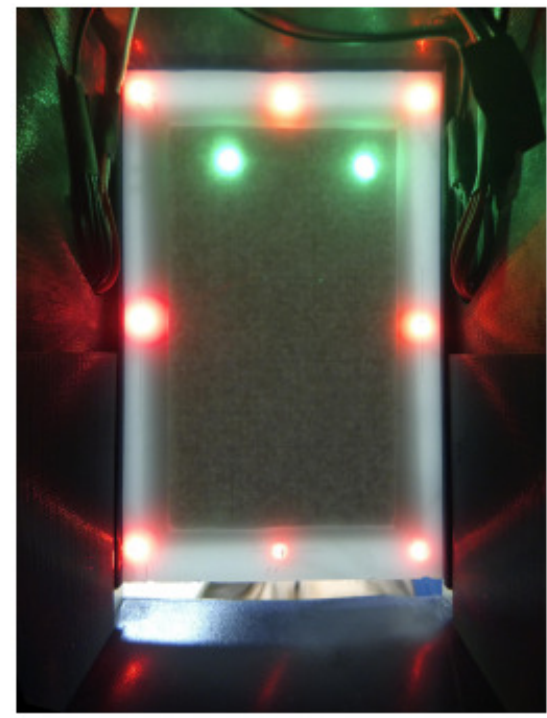

(A)

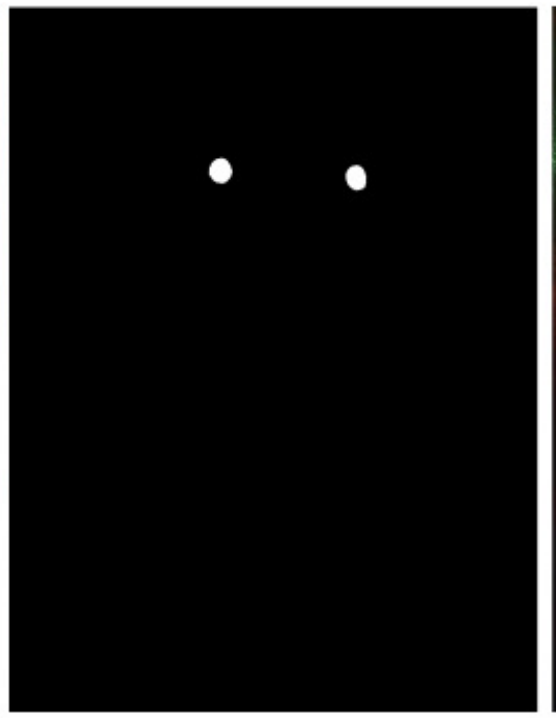

(B)

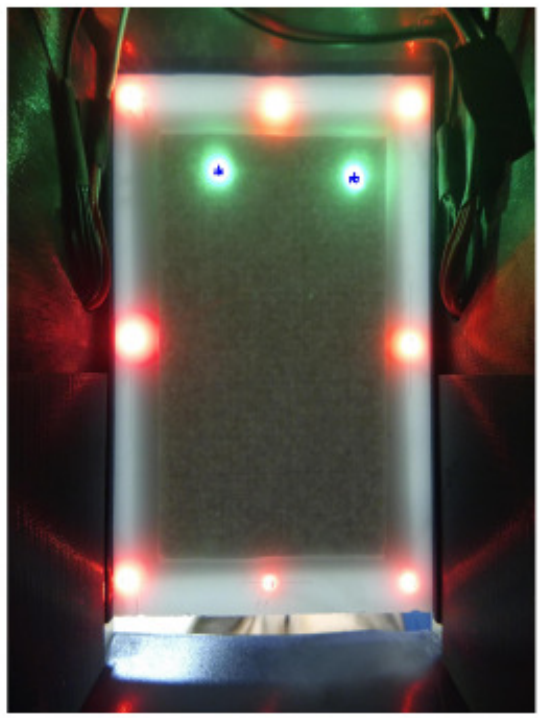

(C)

FIG. 5 INTERMEDIATE PROCESSING STEP SHOWING (A) ORIGINAL IMAGE PRIOR TO PROCESSING, (B) LASER DOT MASK RESULTING FROM COLOR THRESHOLDING PROCEDURE, AND (C) ORIGINAL IMAGE WITH LASER CENTROID LOCATIONS IDENTIFIED

Several algorithms comprise the regionprops ( ) function, but the main interest for this research is the centroid calculation. After the thresholding procedure has cleared all pixels in the image that do not contain data relevant to the green laser dot locations, the regionprops () function is called. The function first reads in the original image and converts it to black and white. For this, all pixels with data relevant to the laser location are assigned the color white (a value of "1" in the image array), and all other pixels are assigned the color black (a value of " 0 " in the image array). The function then fills any small holes existing in the regions of interest to ensure that a continuously filled region exists. The area of the region is then calculated based on pixels contained in each enclosed region. Working row by row, and column by column, the program determines the area contained within each row and each column of the image array. The weighted center of gravity is defined as the following: 


$$
\begin{aligned}
& X_{C o G}=\frac{\sum x_{i} \cdot A_{i}}{\sum A_{i}}(1) \\
& Y_{C o G}=\frac{\sum y_{i} \cdot A_{i}}{\sum A_{i}}(2)
\end{aligned}
$$

where $\mathrm{XCoG}$ and $\mathrm{YCoG}$ are the coordinates of the center of gravity of each laser dot, xi and yi are the center of gravity coordinates of each pixel containing laser data ( $\mathrm{i}=1$ to Nref), and Ai is the area of each pixel [25 to 28].

\subsubsection{Cross-Correlation Techniques}

Cross-correlation was used as an alternative to the centroid technique discussed in Section 2.2.2. Cross-correlation measures the similarity between two signals as a function of distance between the two. Instead of attempting to locate the centroid, cross-correlation attempts to mathematically describe the difference between two signals. This concept can be incorporated into image-based analysis, where data extracted from an image (the "signal" of the image) is compared to a reference image by means of cross-correlation to determine the displacement function between the data from the two images. For discrete functions $m$ and $n$, the cross-correlation function is defined as:

$$
\begin{gathered}
C(k, l)=\sum_{m=0}^{M-1} \sum_{n=0}^{N-1} X(m, n) \bar{H}(m-k, n-l) \\
-(P-1) \leq k \leq M-1 \\
-(Q-1) \leq l \leq N-1
\end{gathered}
$$

where $\bar{H}$ denotes the complex conjugate of $H$, and $k, l$ represent the displacement (lag) row and column indices. The result of cross-correlation analysis produces a value for the shift in each of the two principal axes between the two images, which corresponds to the maximum value of the cross-correlation function. The only variable portion of each image captured by the sensor is the green laser dot locations. Therefore, shifts found during cross-correlation directly correspond to movements observed in the green laser dots. 
Several built-in functions within MATLAB are available to perform the desired cross-correlation procedures. For the purposes of this research, the function $x \operatorname{corr} 2(A, B)$ was used. The $\mathrm{x} \operatorname{corr} 2(\mathrm{~A}, \mathrm{~B})$ function returns the cross-correlation of matrices $A$ and $B$ with no scaling. Upon completion of the $x \operatorname{corr} 2(A, B)$ function, the maximum amplitude of the returned signal from cross-correlation is identified, and assigned to the y principal axis. The ind2sub () function is then used to identify the index location of the signal at the max y-axis value. The extracted $x-y$ coordinate corresponds to the shift between the original image signal, and the image signal of interest.

The $x \operatorname{corr} 2$ () function only produces results to the nearest pixel, so an alternative cross correlation technique was implemented to establish sub-pixel results [29]. Instead of using a zero-padded Fast Fourier Transform (FFT) as with traditional cross correlation techniques used in the $x \operatorname{corr} 2()$ function, the alternative method uses selective up-sampling by a MatrixMultiply Discrete Fourier Transform (DFT). This approach uses all image data points to compute the up-sampled cross correlation in a very small region near the peak of the Fourier Transform. This method has been termed Single-Step DFT algorithm (SSDFT). 


\subsection{TEST SETUPS AND PROCEDURES}

\subsection{Laboratory Study 1: Static Displacements}

The primary goal of the first laboratory study was to take characterize the sensor's response at measurement distances, $\mathrm{L}=3.05 \mathrm{~m}(10.0 \mathrm{ft}), 15.2 \mathrm{~m}(50 \mathrm{ft})$, and $30.5 \mathrm{~m}(100 \mathrm{ft})$ under static displacements. Results for this study are presented and discussed in Section 4.1.

Figure 6(A) shows the fixed part of the sensor, which is comprised of a steel bracket approximately $457 \mathrm{~mm}$ (18 in) tall, secured to a heavy steel base. The laser emitters were fixed to the steel bracket using electrical tape. After securing each laser emitter to the fixed support, vertical and horizontal micro-adjusters located on each laser emitter were used to fine-tune laser dot locations on the translucent sensor panel at the beginning of the study. As a starting point, the green lasers were oriented such that they were located approximately midway between the vertical maximum and minimum extents of the translucent panel. Figure 6(B) shows the configuration of the movable part of the sensor. The sensor base was comprised of stacked HSS sections, welded together. A vice clamp was connected to the topmost HSS section. A highprecision digital caliper (Brand: Neiko (Zhejiang Kangle Group, Wenzhou, China), Model: 01407A) was fixed between the vice clamp and a length of angle steel, which was used as a platform for the sensor to mount against. The sensor case was affixed to the angle steel platform with a strong magnet placed on the inside of the sensor case. The angle steel created a movable platform for the sensor where precise vertical displacements could be measured.

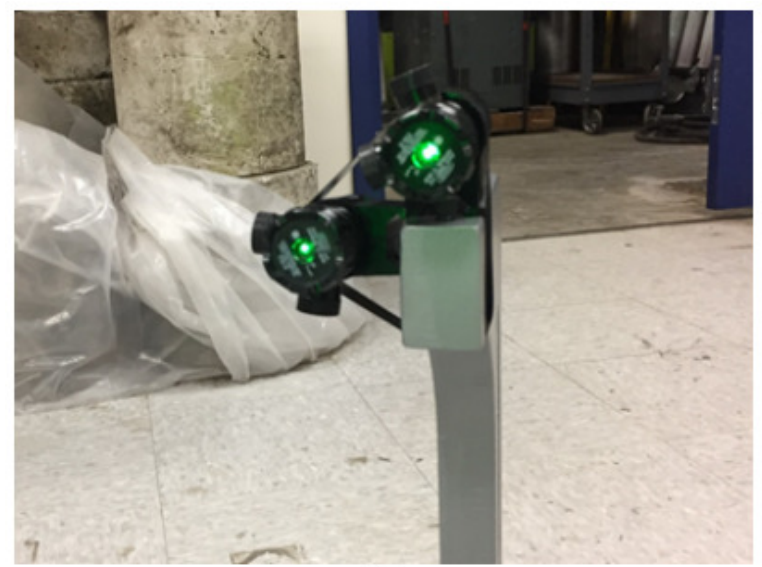

(A)

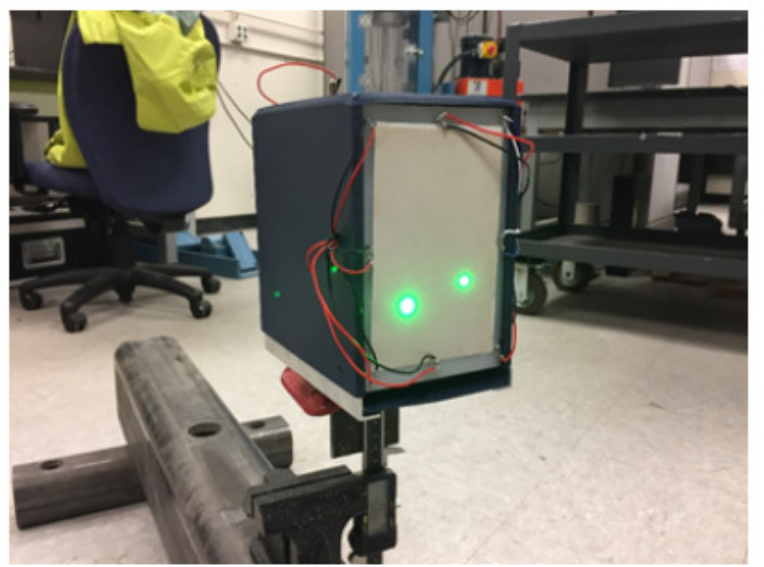

(B)

FIG. 6 PHOTO OF SENSOR PROTOTYPE: (A) FIXED AND (B) MOVABLE PART OF THE SENSOR USED IN LABORATORY STUDY 1 
At each measurement distance, the sensor was moved vertically in approximately $8 \mathrm{~mm}(0.32 \mathrm{in})$ increments until the lasers were at the extreme end of the translucent panel, then the sensor was moved vertically in the opposite direction, first by $4 \mathrm{~mm}(0.16 \mathrm{in})$, then subsequently in $8 \mathrm{~mm}$ (0.32 in) increments so that measurements were available at approximately $4 \mathrm{~mm}$ (0.16 in) increments across the face of the translucent panel. At each measurement location, three images were recorded. Image resolution used during image data collection was 3000 x 4000 pixels and images were recorded in the RGB color space. Processed data for each of the three images captured were compared to determine the amount of noise/variation resulting from each of the processing techniques.

\subsection{Laboratory Study 2: Effect of Lighting Conditions}

The second laboratory study aimed to gather data on the sensitivity of the sensor to varying lighting conditions. Results for this study are presented and discussed in Section 4.2.

The fluorescent indoor lighting of the lab was used as the reference lighting condition. The sensor was set up in the same manner as described in Section 3.1, using measurement distance, $\mathrm{L}$ $=7.62 \mathrm{~m}(25 \mathrm{ft})$. Similar to Laboratory Study 1, image resolution used during image data collection was 3000 x 4000 pixels and images were recorded in the RGB color space. With the two laser dots focused near the center portion of the translucent panel, three images were recorded under reference conditions. Next, a bright fluorescent lamp was placed close to the sensor so that the entire translucent panel was completely illuminated. Three images were then recorded under these lighting conditions. The intent of this lighting condition was to create "direct sun" exposure of the sensor during testing. Next, the fluorescent lamp was oriented so that only part of the translucent panel was illuminated. The lamp was oriented such that one of the green laser dots was within the illuminated portion of the panel, and one green laser dot was located within the unilluminated portion of the panel. The intent of this was to provide a "partial shade" condition. As before, three images were recorded under these conditions. For the final lighting condition, all lights within the lab, including the fluorescent lamp were turned off, with the intent to explore the functionality of the sensor at night. Figure 7 provides sample images 
recorded during each of the four lighting conditions, along with the exposure information for each.

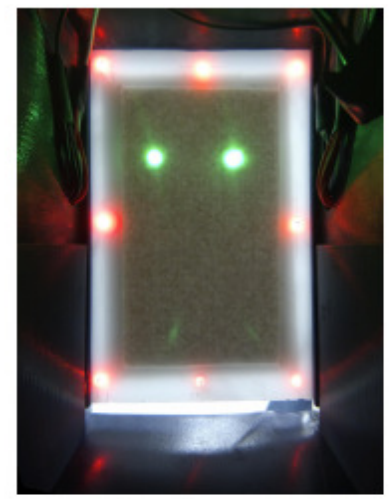

Indoor Fluorescent Lighting Condition ISO 343 , f2.8, $1 / 7 \mathrm{sec}$

(A)

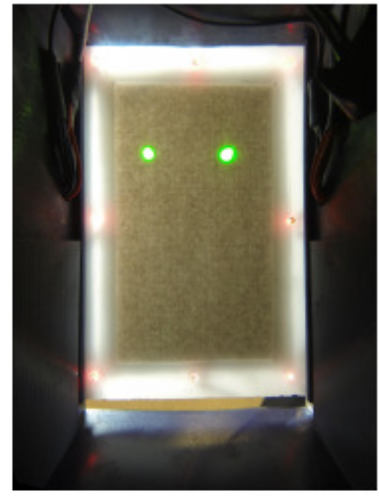

Direct Sunlight Lighting Condition ISO 202 , f2.8, 1/30 sec

(B)

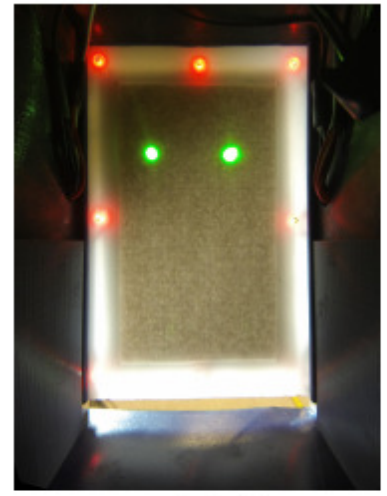

Partial Shade Lighting Condition ISO 400 , f2.8, 1/29 sec

(C)

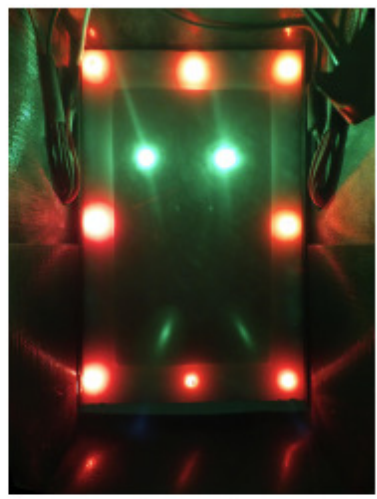

Complete Darkness Lighting Condition ISO $400, \mathrm{f} 2.8,1 / 2 \mathrm{sec}$ (D)

FIG. 7 SAMPLE IMAGES TAKEN UNDER (A) INDOOR FLUORESCENT, (B) DIRECT SUNLIGHT, (C) PARTIAL SHADE, AND (D) COMPLETE DARKNESS LIGHTING CONDITIONS

\subsection{Field Study 1: Monitoring of a Five-Story Building under Ambient Loading Conditions}

The first field study was performed on the Engineering Building located on the Portland State University campus. The Engineering Building has 5 above-grade levels and 1 below-grade level

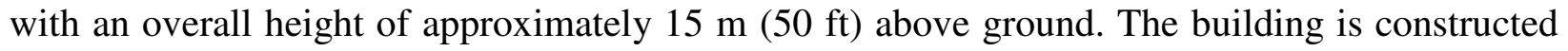
of steel moment frames with pre-stressed concrete slabs at each level. The main stairwell of the building is open, providing a direct view from the lowest level to the top level. The intent of this study was to capture lateral deflections and rotation of the structure under low-moderate wind conditions. The laser emitters were fixed to the floor slab on the top level and positioned in a manner to project the lasers straight down the stairwell to the lowest level. Figure 8(A) shows the configured laser setup, i.e. fixed part of the sensor. The movable part of the sensor was located on the lowest level and positioned with the translucent panel pointing straight up, with direct line-of-sight to the laser emitters (see Figure 8(B)). 


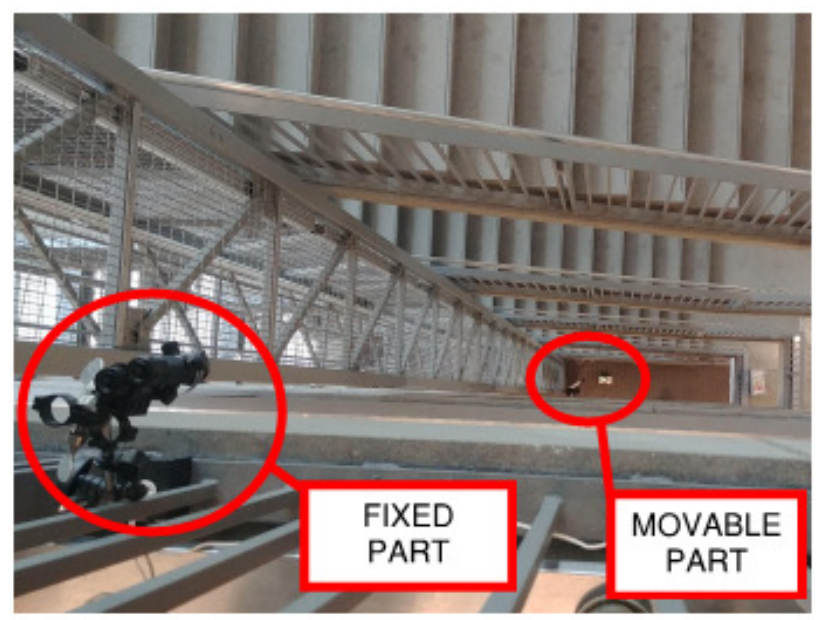

(A)

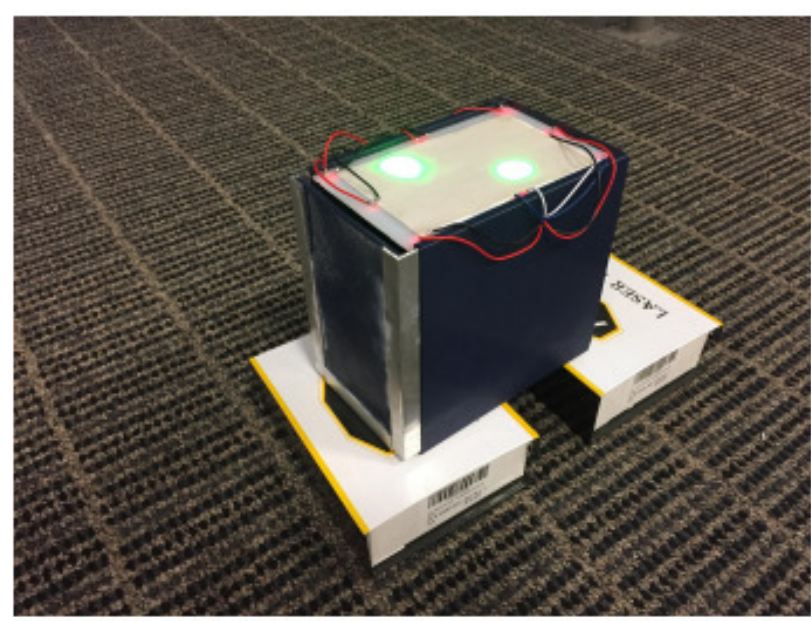

(B)

FIG. 8 PHOTOS SHOWING SENSOR CONFIGURATION FOR FIELD STUDY 1: (A) VIEW FROM TOP TO BOTTOM OF STAIRCASE SHOWING BOTH SENSOR PARTS AND (B) MOVABLE PART OF THE SENSOR WITH LASER DOTS

A frame rate of 30 frames per second was used for all recordings. This provided a Nyquist frequency of $15 \mathrm{~Hz}$, well beyond the expected natural frequency of the structure. Individual frames extracted from the videos were 2704 by 1536 pixels. Three separate video recordings were taken during the study. Two of the recordings had a length of $30 \mathrm{~s}$, and the final video had a length of $60 \mathrm{~s}$. Upon completion, the recorded videos were imported into MATLAB for processing. Individual image frames were extracted from each video file and stored in a matrix. Similar to Lab Studies \#1 and \#2, individual image frames extracted from the videos were processed using the three processing techniques to determine the displacement of each green laser dot. The displacements for each laser were stored along with frame number to create a displacement-vs-time array. A Fast-Fourier-Transform was performed on each dataset to identify primary frequencies of vibration captured by the sensor. This was used to compare with the theoretical first mode of vibration of the structure obtained from current building code formulas, and to identify additional frequencies present in the data.

In addition to interpreting results for displacement in the $\mathrm{x}$ and $\mathrm{y}$-directions, rotational characteristics of the data were analyzed [30 to 32]. The locations of the two green laser dots extracted from the first frame of each video were used as the reference location. The vector slope and magnitude between these initial two laser dot locations were calculated and stored. The 
same calculation was carried out for each subsequent image frame. The angle between the base vector and a frame of interest was calculated using the following formula:

$$
\theta=\cos ^{-1} \frac{\vec{a} \cdot \vec{b}}{\|a\|\|b\|}
$$

This equation results only in positive values of theta. To determine the sign of the angle, the difference in the slope between the two laser dots of the image frame of interest and the base image frame were calculated and compared. Positive values were assigned a positive value of theta, and negative values were assigned a negative theta. Like the data located in the $\mathrm{x}-$ and $\mathrm{y}-$ directions, a Fast-Fourier-Transform was performed on each dataset for the rotational direction. This data was also compared to the theoretical natural period of vibration of the structure obtained from current building code formulas.

For the calculation of the theoretical natural period of vibration of the structure, methods described in ASCE 7-16, Chapter 12.8 were utilized [33]. The following equations were used to approximate the natural period of vibration and natural frequency of the structure:

$$
\begin{aligned}
& T_{a}=C_{t} h_{n}^{x} \\
& f_{a}=1 / T_{a}
\end{aligned}
$$

where $h_{n}$ is the structural height of the structure, and $C_{t}$ and $\mathrm{x}$ are coefficients taken from ASCE 7-16, Table 12.8-2 $\left(C_{t}=0.028\right.$ and $\mathrm{x}=0.8$ for steel moment-resisting frames $)$ [33]. Floors heights were approximated at $3 \mathrm{~m}(10 \mathrm{ft})$, for a total above-ground height of $15 \mathrm{~m}(50 \mathrm{ft})$. This results in a theoretical period of vibration $\mathrm{Ta}=0.64$ seconds, and a fundamental frequency, $\mathrm{fa}=$ $1.56 \mathrm{~Hz}$.

Results for this study are presented and discussed in Section 4.3.

\subsection{Field Study 2: Monitoring of a Bridge under Various Loading Conditions}

The second field study was designed to capture vertical deflections at the mid-span of a bridge during dynamic loading. The Pedestrian Bridge, located on the Reed College campus in Portland, 
Oregon, was chosen for this study. The pedestrian bridge has spans of 31 (101.7 ft), 36 (118.1 $\mathrm{ft})$, and $31 \mathrm{~m}(101.7 \mathrm{ft})$, for a total length of $98 \mathrm{~m}(321.5 \mathrm{ft})$. The bridge is $3 \mathrm{~m}(10 \mathrm{ft})$ wide outto-out, with a concrete deck bearing upon concrete box girders. Figure 9 provides an elevation view of the structure.

The movable part of the sensor was placed at mid-span of the center location of the bridge. The fixed part was located just off the structure near the southwest corner, to maintain direct line-ofsite with the movable part of the sensor, which consisted of the laser emitters affixed to a steel vise.

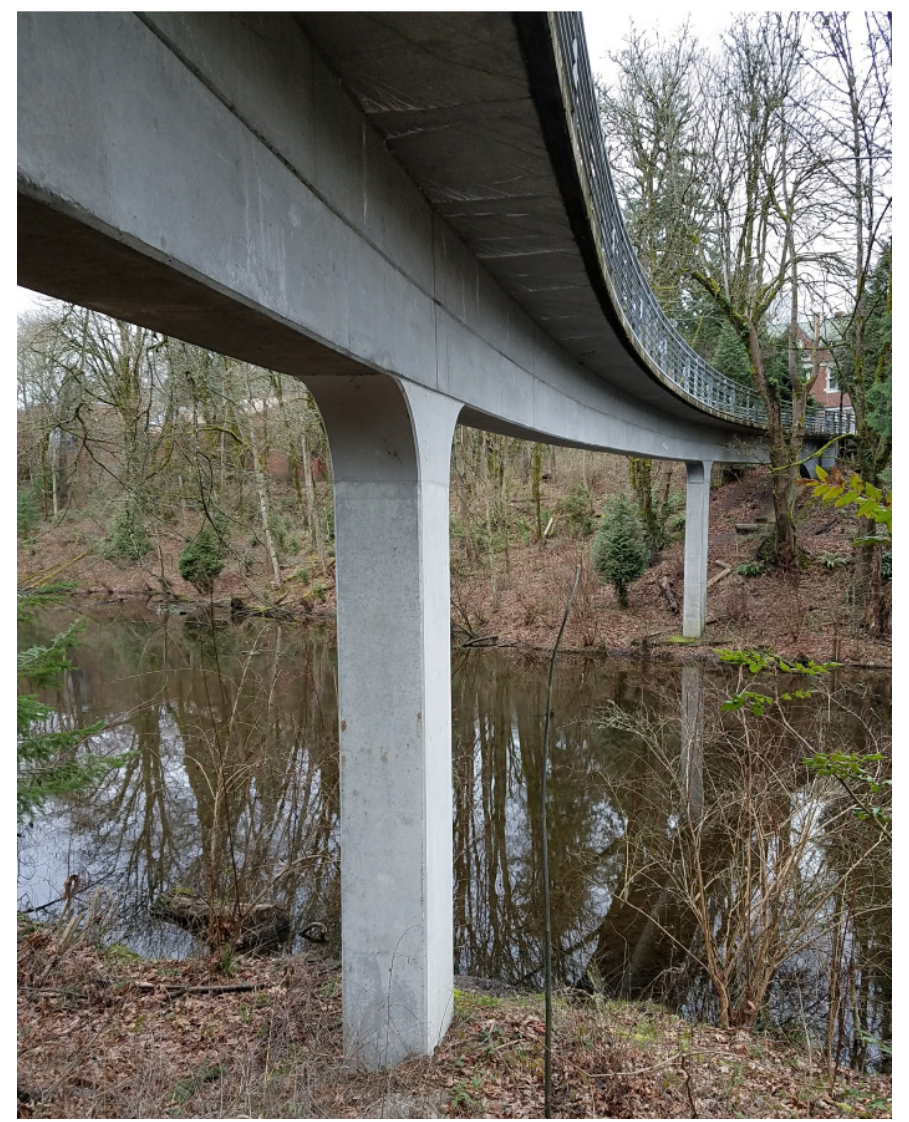

FIG. 9 ELEVATION VIEW OF PEDESTRIAN BRIDGE AT REED COLLEGE IN PORTLAND, OREGON

Dynamic loading of the structure was accomplished by having two individuals jump in unison at the approximated fundamental period of the structure, fa $=5 \mathrm{~Hz}$. A phone-based application 
(Physics Toolbox) was used to capture the accelerations generated by the loading for comparison.

Results for this study are presented and discussed in Section 4.3. 


\subsection{RESULTS AND DISCUSSION}

\subsection{Laboratory Study 1}

The objective of this study was to determine the sensor's conversion factor, its accuracy depending on the used image processing technique, as well as demonstrate the improvement due to image distortion correction.

\subsubsection{Conversion Factor}

Figure 10 shows correlation plots for each of the three measurement distances, L comparing the recorded caliper reading (measured in $\mathrm{mm}$ ) with the computed displacement in the vertical axis (measured in pixels) using the Single-Step DFT technique. A first-order polynomial-curve fit function was found as the best fit with an average coefficient of determination, R2 $=0.9999$ for all measurement distances. 95\% prediction limits were computed and used as a measure of accuracy of the sensor, which is discussed in detail in Section 4.1.2. The inverse of the slope of the curve fit function can be interpreted as the conversion factor, $\mathrm{C}$, which was found to be independent of the measurement distance:

$$
C=\frac{1}{0.0546 \frac{\mathrm{mm}}{\text { pixel }}}=18.3 \frac{\text { pixel }}{\mathrm{mm}}\left(465 \frac{\text { pixel }}{\text { in }}\right)(7)
$$

This conversion factor was used throughout the remainder of the laboratory tests. 

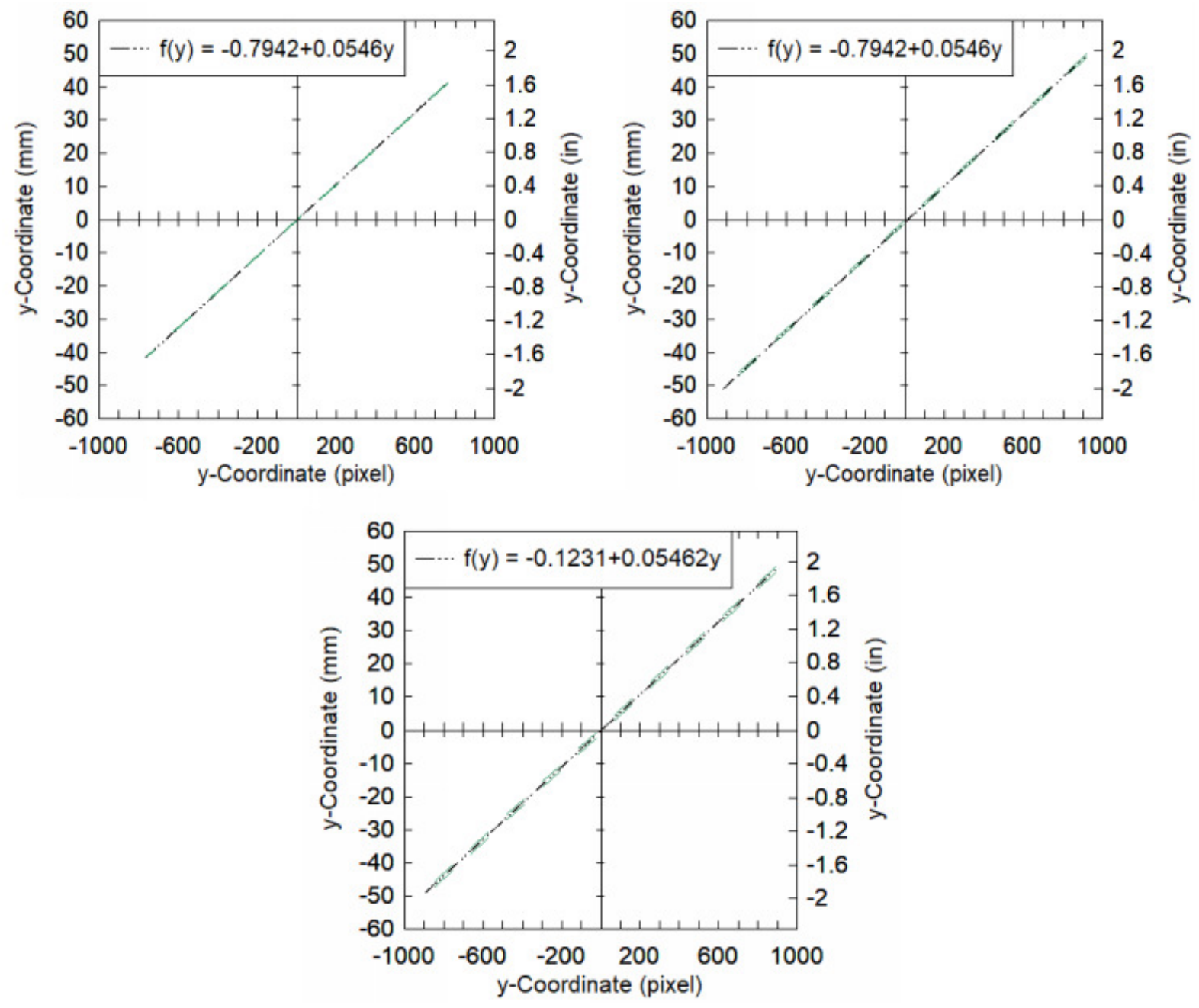

FIG. 10 CORRELATION PLOTS FOR THE SINGLE-STEP DFT TECHNIQUE FOR ALL MEASUREMENT DISTANCES WITH CURVE FIT FUNCTIONS: (A) 3.05 M (10 FT), (B) $15.2 \mathrm{M} \mathrm{(50} \mathrm{FT),} \mathrm{(C)} 30.5$ M (100 FT). GREEN DASHED LINES REPRESENT 95\% PREDICTION LIMITS

\subsubsection{Sensor Accuracy}

The accuracy of the sensor was taken as the $95 \%$ prediction limits obtained for the curve fit described in Section 4.1.1 and computed for all three processing techniques for comparison. In addition, processing times between the three techniques were compared to determine the overall processing cost and efficiency of each technique. Figure 11 illustrates the mean 95\% prediction limits versus measurement distance for each of the three processing techniques and how they compare to each other. 


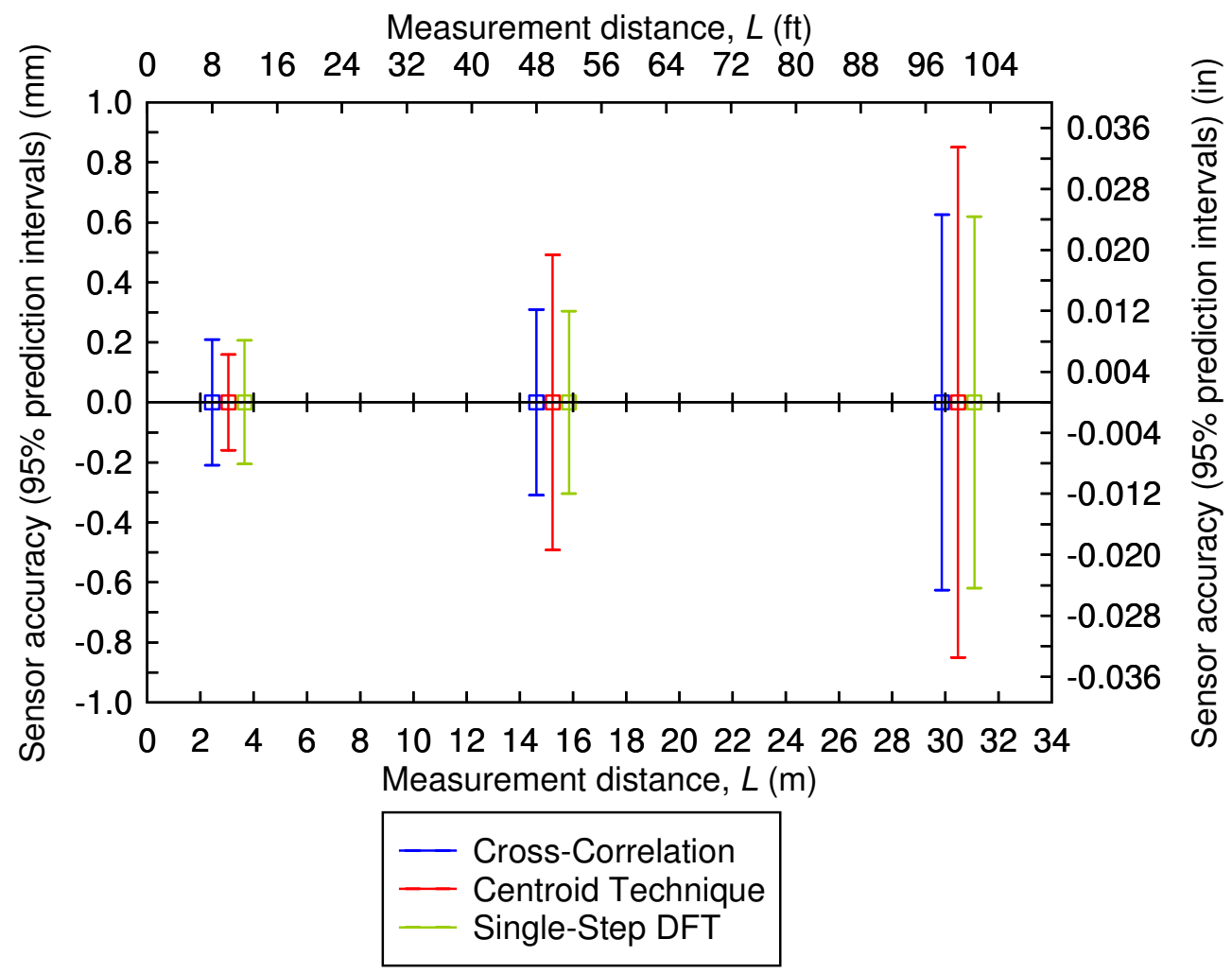

FIG. 11 SENSOR ACCURACY VERSUS MEASUREMENT DISTANCE FOR CROSS-CORRELATION, SINGLE-STEP DFT, AND CENTROID TECHNIQUES

A linear fitting was performed between confidence interval and measurement distance for each of the three techniques. For the centroid technique, the equation is $\mathrm{C}=0.0251 \cdot \mathrm{L}+0.0926$, where $\mathrm{C}$ is the $95 \%$ confidence interval and $\mathrm{L}$ is the length $(\mathrm{R} 2=0.9983)$. There is an intrinsic uncertainty of $0.0926 \mathrm{~mm}(0.00365 \mathrm{in})$ and a progressive uncertainty of $0.0251 \mathrm{~mm} / \mathrm{m}(0.00030 \mathrm{in} / \mathrm{ft})$.

For the cross-correlation methodology, the equation is $\mathrm{C}=0.0155 \cdot \mathrm{L}+0.1308$, where $\mathrm{C}$ is the $95 \%$ confidence interval and $\mathrm{L}$ is the length $(\mathrm{R} 2=0.9491)$. There is an intrinsic uncertainty of 0.1308 $\mathrm{mm}(0.00515 \mathrm{in})$ and a progressive uncertainty of $0.0155 \mathrm{~mm} / \mathrm{m}(0.00019 \mathrm{in} / \mathrm{ft})$. This would indicate that the cross-correlation methodology is better suited for larger measurement distances than shorter measurement distances.

Similarly, a linear fitting was performed for the single-step DFT technique. For this, the equation is $\mathrm{C}=0.0152 \cdot \mathrm{L}+0.1298$, where $\mathrm{C}$ is the $95 \%$ confidence interval and $\mathrm{L}$ is the length ( $\mathrm{R} 2=0.9402)$. 
There is an intrinsic uncertainty of $0.1298 \mathrm{~mm}(0.00511 \mathrm{in})$ and a progressive uncertainty of $0.0152 \mathrm{~mm} / \mathrm{m}(0.00018 \mathrm{in} / \mathrm{ft})$. This would indicate that the single-step DFT technique is slightly better than the standard cross-correlation technique for both shorter and longer measurement distances.

Figure 12 illustrates the comparison between average processing times per image/frame and processing technique. The shortest processing time per frame was observed when using the centroid detection technique, averaging 0.313 seconds per image/frame. The single-step DFT technique averaged $1056.5 \%$ longer processing times than the centroid technique (3.62 seconds per image/frame). The standard cross-correlation technique averaged $27797.8 \%$ longer processing times than the centroid technique ( 87.32 seconds per image/frame).

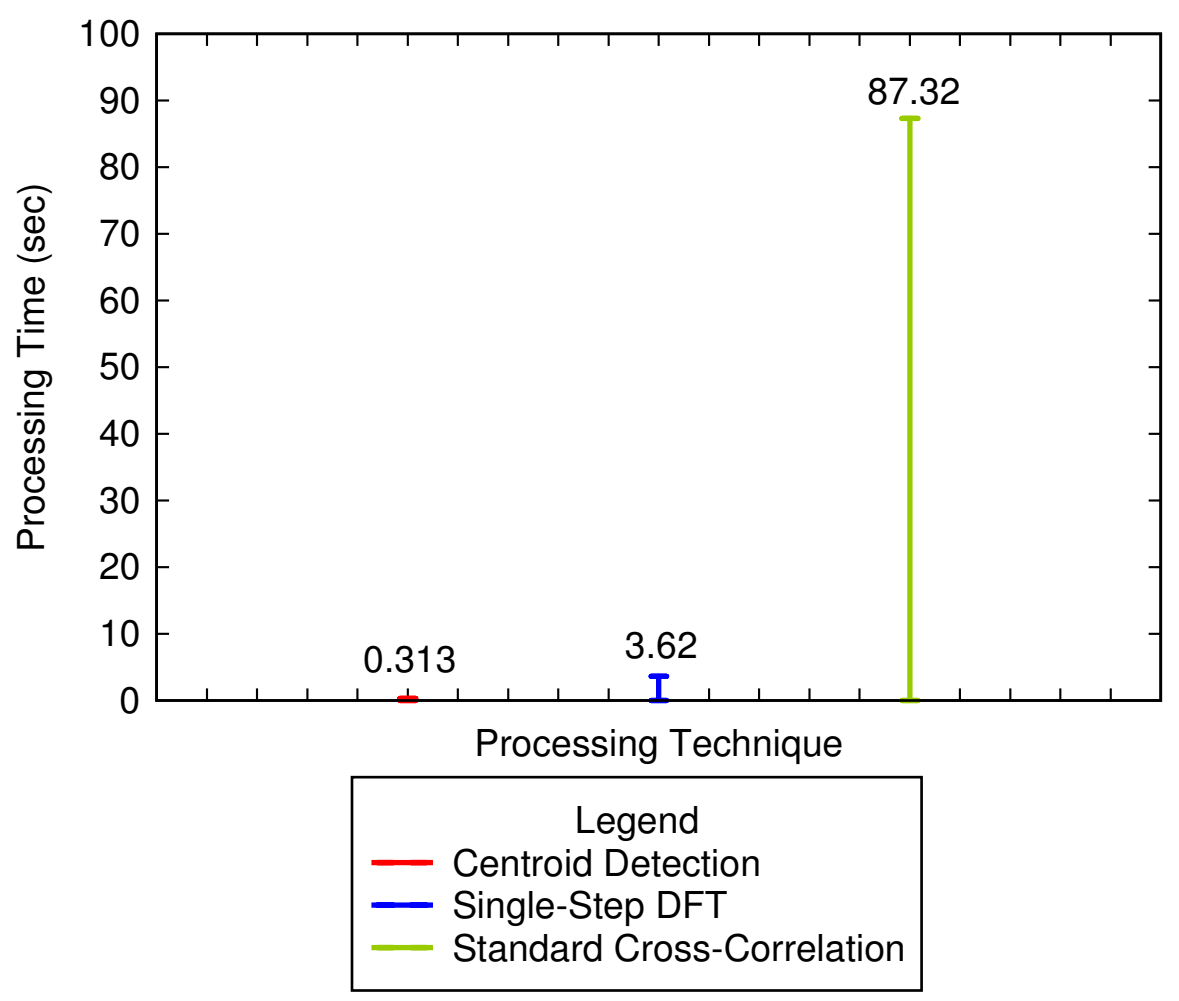

FIG. 12 AVERAGE PROCESSING TIME VERSUS PROCESSING TECHNIQUE 


\subsubsection{Distortion Correction}

Pre-distortion and post-distortion correction results were compared to determine the accuracy gained from the distortion correction step for the single-step DFT technique. Figure 12 shows the 95\% prediction intervals for pre- and post-correction processing as a function of the measurement distance, $\mathrm{L}$. For $\mathrm{L}=3.05 \mathrm{~m}(10 \mathrm{ft})$, the $95 \%$ prediction limits decreased by $84.5 \%$,

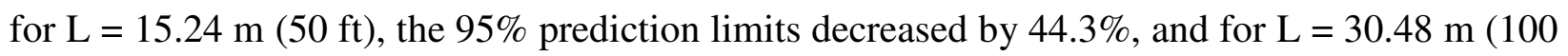
$\mathrm{ft}$ ), the $95 \%$ prediction limits decreased by $24.4 \%$. As can be observed, the distortion correction step significantly improves the accuracy of the sensor, with the greatest improvement seen for shorter measurement distances.
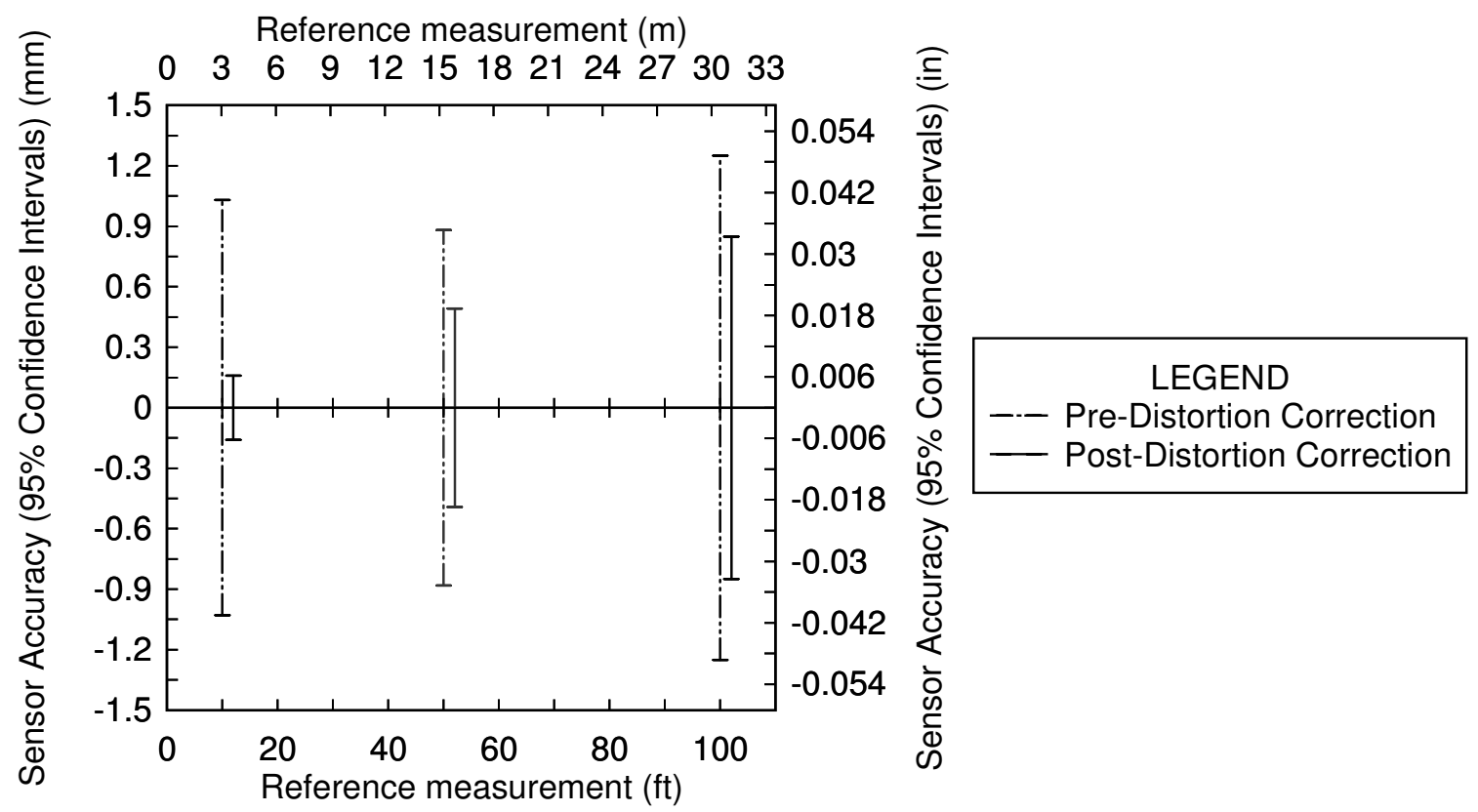

FIG. 12 SENSOR ACCURACY FOR PRE-DISTORTION AND POST-DISTORTION CORRECTION PROCESSING VERSUS MEASUREMENT DISTANCE (CENTROID TECHNIQUE)

\subsection{Lab Study 2}

For each of the lighting conditions, the three images were processed and compared to determine the level of noise contained in the image data. Since both parts of the sensor remained fixed during this study, any deviation in the calculated displacements was considered as noise. Several factors could lead to the deviations observed in the processed data, but the most likely 
contributors would be small inconsistencies in the weighted average approach to calculating the centroid (centroid technique only) and minute ambient vibrations of the test setup. As discussed in Section 3.2, images recorded under normal indoor fluorescent lighting were used as the reference condition. Specifically, the location from the three images captured under this lighting condition were used as the reference location. As would be expected, the indoor fluorescent lighting condition, when compared to the reference location, had the smallest deviation, averaging $0.007 \%$. The difference between the direct sunlight and the reference condition averaged $0.058 \%$. Partial shade condition 1 deviation from the reference condition averaged $0.054 \%$. Partial shade condition 2 deviation from the reference condition averaged $0.080 \%$. Finally, the full darkness lighting condition had the largest deviation from the reference condition, averaging $0.164 \%$. The results show that the proposed sensor shows some relatively minor sensitivity to different lighting conditions.

\subsection{Field Study 1}

Figure 13 shows displacement vs. time for each laser in the $\mathrm{x}$ and $\mathrm{y}$-directions. Figure 14 shows rotation vs. time for the first recording taken.
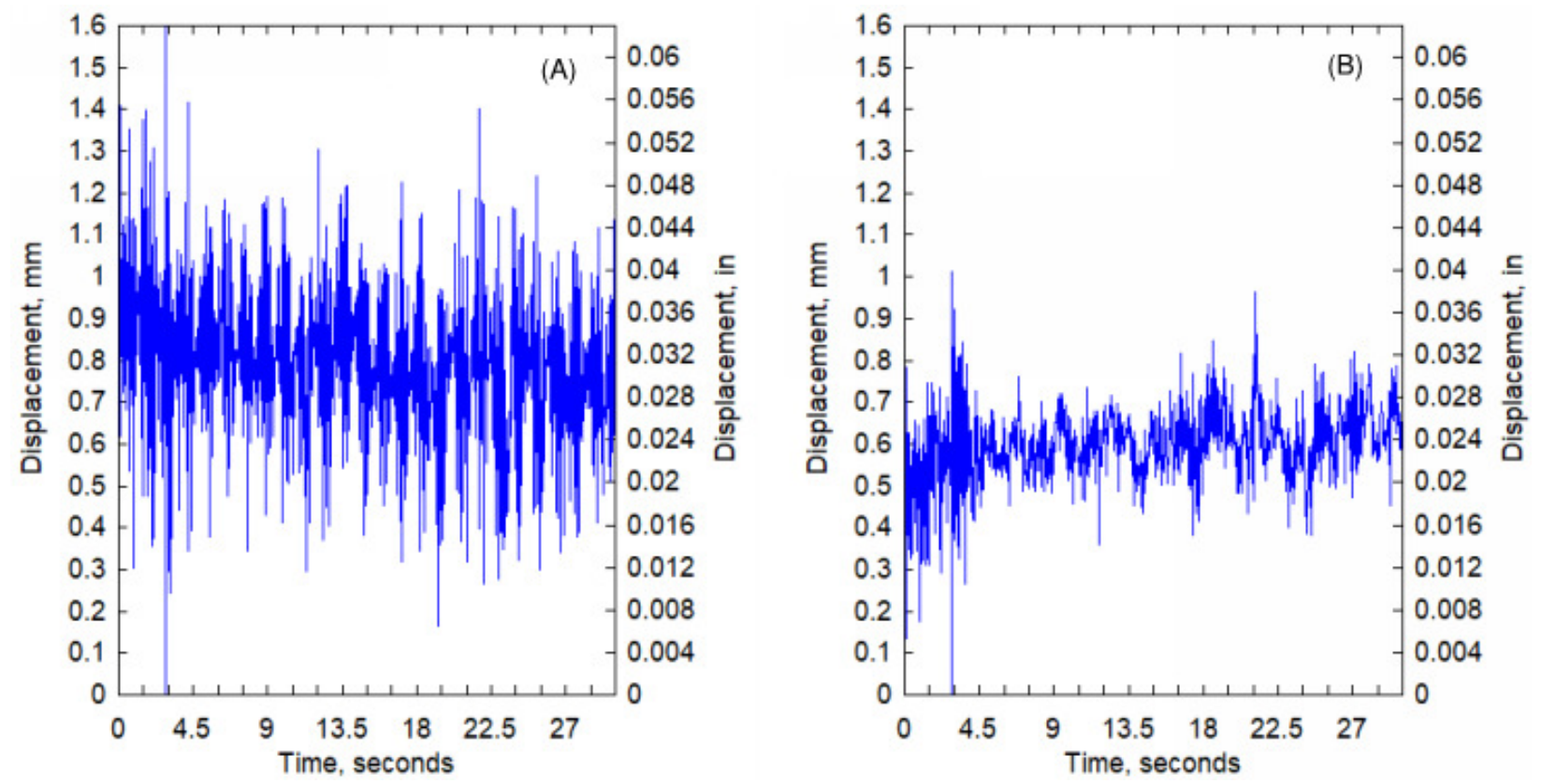

FIG. 13 DISPLACEMENT MEASUREMENTS TAKEN IN THE X AND Y-DIRECTIONS FOR FIELD STUDY 1 USING THE SINGLE-STEP DFT TECHNIQUE: (A) LASERS IN THE X-DIRECTION, (B) LASERS IN THE YDIRECTION 


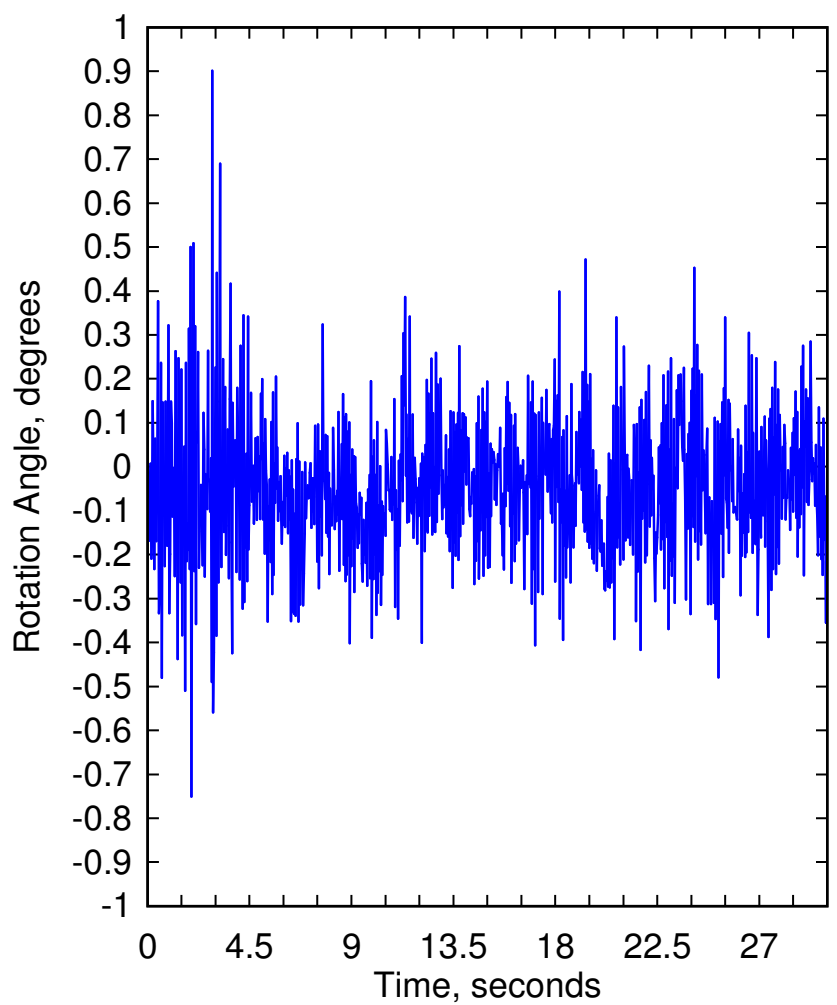

FIG. 14 ROTATION MEASUREMENTS COMPUTED FROM STUDY 1 USING THE SINGLE-STEP DFT TECHNIQUE

First, this test demonstrates that the sensor can provide data about horizontal displacements and rotation of the building, which is of interest by itself.

Moreover, a fast Fourier transform (FFT) was performed for each laser measurement shown in Fig. 13 in the $\mathrm{x}$ and $\mathrm{y}$-directions. In addition, an FFT was performed for the angular rotation measured between the two lasers. Figure 15 shows the results of the FFT for laser 1. Key frequencies are labeled, along with the ASCE 7-16 calculated fundamental natural vibration frequency, fa $=1.56 \mathrm{~Hz}$, which is marked with a vertical red bar. For laser 1, a frequency peak at $1.73 \mathrm{~Hz}$ can be observed, which is close to the frequency estimated using the ASCE 7-16 formula. Due to the presence of several external excitations on the structure (e.g. people moving, activity in the laboratories, mechanical machinery operations, vehicular traffic outside the building, etc.) and the relatively low wind speeds observed during testing, it could not be conclusively determined whether or not the first fundamental frequency of the building was 
captured by the sensor. Additional testing under higher wind conditions may provide more conclusive results.
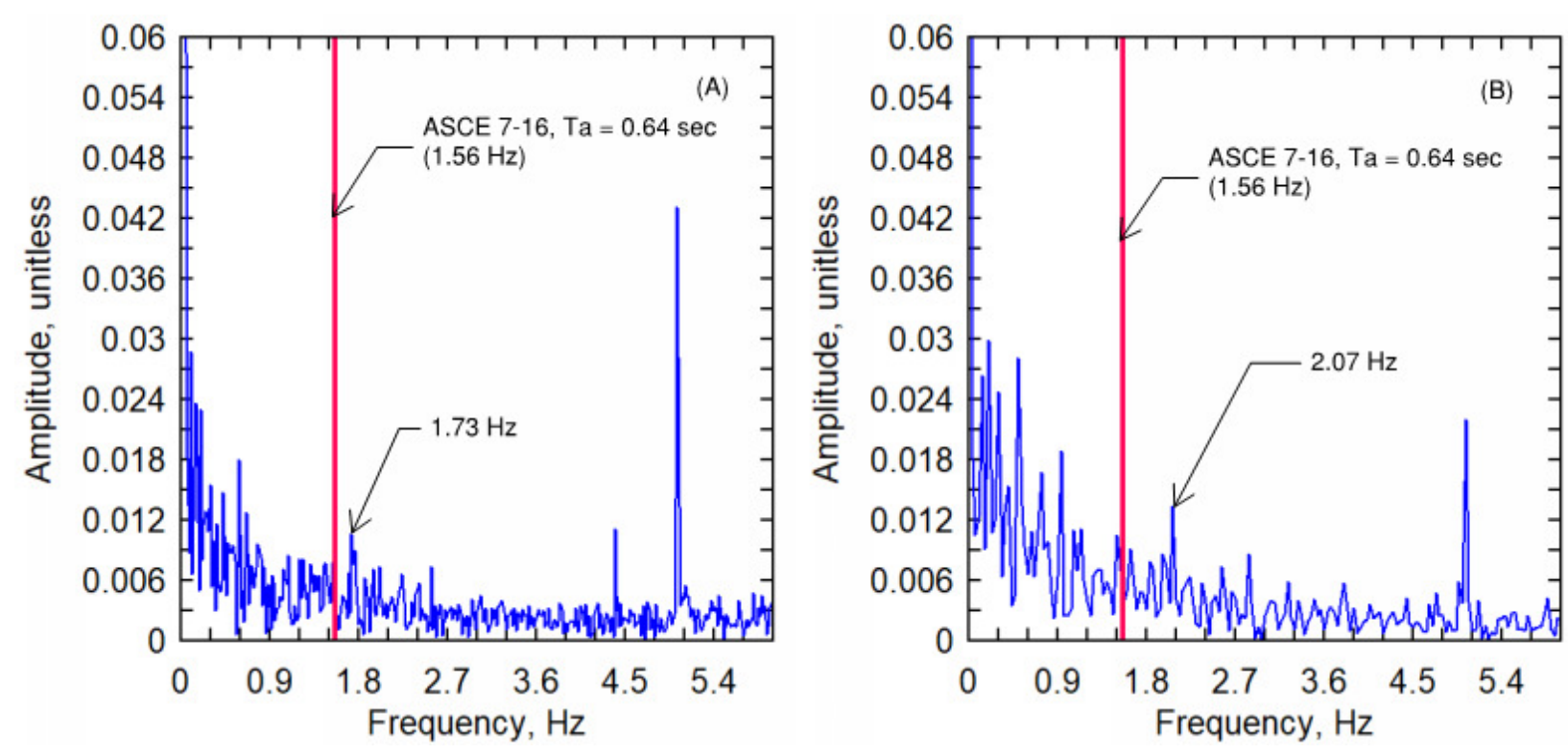

FIG. 15 FAST FOURIER TRANSFORM RESULTS FROM THE FIRST TEST IN FIELD EXPERIMENT \#1: (A) X-COORDINATE, (B) Y-COORDINATE

\subsection{Field Study 2}

For the dynamic pedestrian loading on the bridge, two individuals as described in Section 3.4 jumped in time at the approximated first fundamental frequency of the structure ( $\mathrm{fa}=5.0 \mathrm{~Hz}$ ). The displacement-vs-time recordings taken using the sensor are shown in Figure 16(A). Displacements with amplitudes ranging from $+/-38.92 \mathrm{~mm}(+/-1.53 \mathrm{in})$ were observed. 


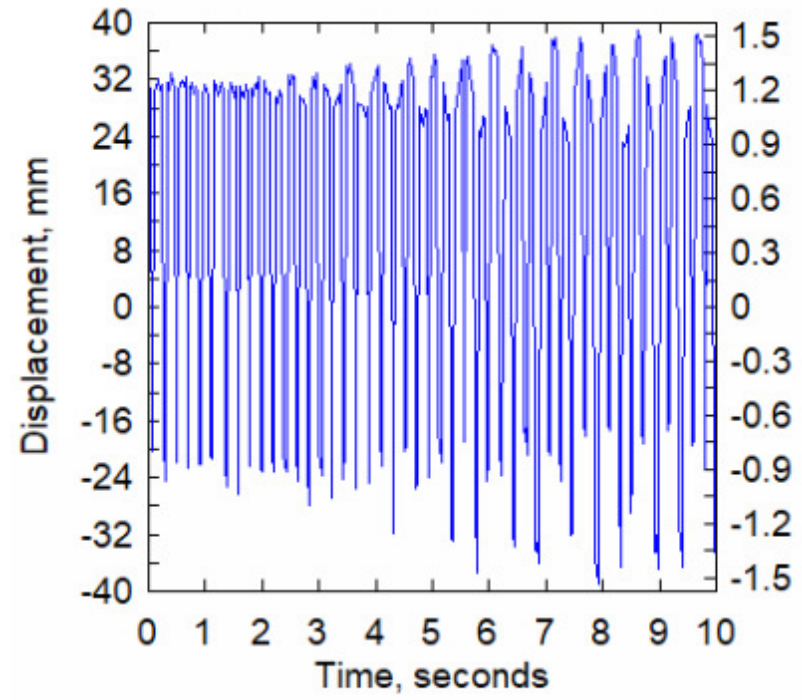

(A)

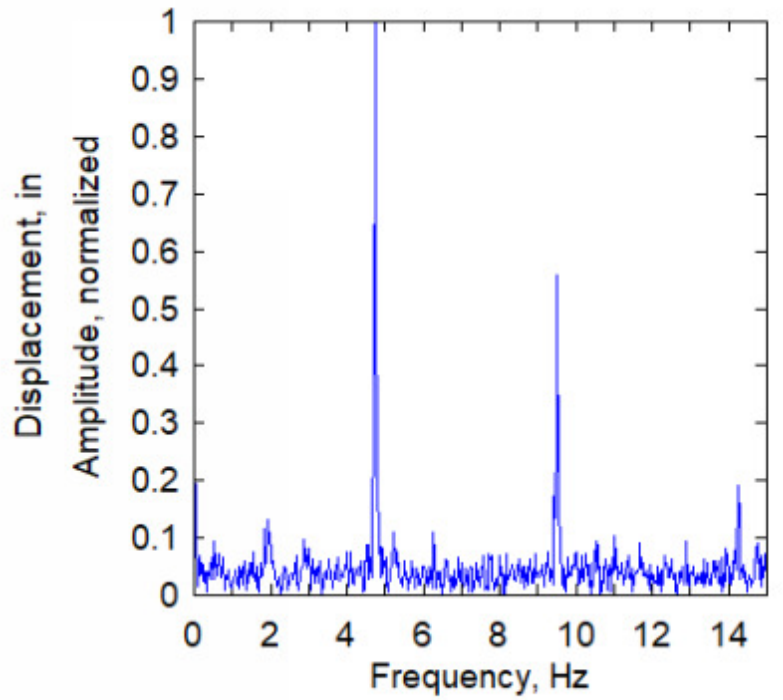

(B)

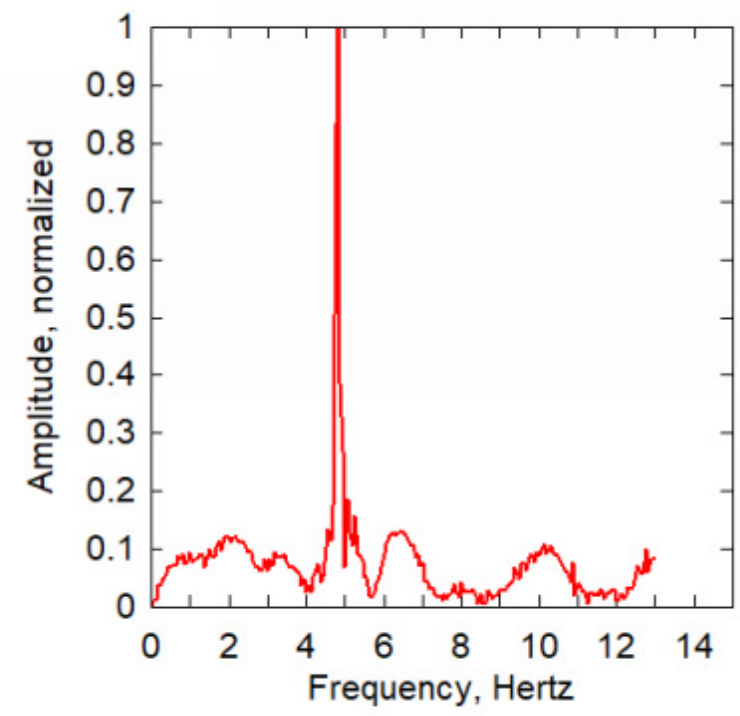

(C)

FIG. 16 (A) DISPLACEMENT MEASUREMENTS AND (B) FAST-FOURIER TRANSFORM IN THE YDIRECTION FOR LASER 1 DURING TEST 1 OF FIELD STUDY 2 USING THE SINGLE-STEP DFT TECHNIQUE AND (C) FAST FOURIER TRANSFORM RESULTS FROM ACCELEROMETER IN FIELD EXPERIMENT \#2 IN THE Z-DIRECTION

An FFT was performed on the displacement data recorded by the sensor to identify dominant frequencies within the recorded data. Figure 16(B) shows the results of the FFT performed on data collected from laser 1 from the first test. Peak frequencies identified were $4.74 \mathrm{~Hz}, 9.51 \mathrm{~Hz}$, and $14.25 \mathrm{~Hz}$. 
The same FFT procedure was performed on the data collected from the accelerometer used to take measurements during the experiment. Figure 16(C) shows the results of the FFT procedure. A peak frequency was identified at $4.81 \mathrm{~Hz}$ which closely agrees with the peak frequency obtained from the sensor displacement data.

The frequency of $4.98 \mathrm{~Hz}$ is in the range of what would be expected for a bridge of this span, construction material, and design. 


\subsection{SUMMARY AND CONCLUSIONS}

With the rate of advancement in video-based technology and image processing software, it is likely that the accuracy, availability, and applicability of laser and video-based solutions will continue to improve.

Due to the direct correlation between deflection and overall structure serviceability, having a method of measuring deflections on structures is a high priority, specifically when it comes to tracking long-term changes in deflections. Having a solution that is accurate, repeatable, and cost-effective in a wide variety of environmental conditions is crucial. Advances in video-based sensors and video processing therefore offer new opportunities in the field of structural health monitoring.

Based on the results presented, a laser and video-based displacement sensor is a viable solution for the monitoring of static and dynamic deflections of bridges (as well as other structures). Although further research and development is needed before this technology can be widely used in the field, initial results are promising. This technology is capable of accurately measuring displacements as small as $0.2 \mathrm{~mm}$ with frequencies up to $30 \mathrm{~Hz}$, under widely varying lighting conditions.

Three processing techniques were employed and compared to determine the most accurate and efficient methodology for tracking displacements with the sensor. Although the centroid detection technique had the greatest advantage with regards to efficiency, the single-step DFT provided the greatest accuracy while still providing reasonably efficient processing times (3.62 seconds per image/frame).

The focus of these initial experiments was aimed at determining the accuracy that could be provided in the measurement of static and dynamic displacements in structures. Further research includes characterization of the sensor for evaluating the sensor's performance for in-field measurements on a variety of structures and long-term under a variety of environmental conditions. 


\subsection{PATENTS}

A Spanish patent (patent no: ES 2684134 B2) has been granted [34]. 


\subsection{REFERENCES}

1. AASTHO. LRFD Bridge Design Specifications, 8th Edition. American Association of State Highway and Transportation Officials 2017.

2. Shan, B.; Wang, L.; Huo, X.; Yuan, W.; Xue, Z. A bridge deflection monitoring system b ased on CCD. Advances in Materials Science and Engineering 2016, vol. 2016, ID 48573 73,10 pages.

3. Hoag, A.; Hoult, N.; Take, W.; Moreu, F.; Le, H.; Tolikonda, V. Measuring displacements of a railroad bridge using DIC and accelerometers. Smart Structures and Systems 2017, vol. 19, no. 2.

4. Khuc, T.; Catbas, F.N. Computer vision-based displacement and vibration monitoring without using physical target on structures. Structure and Infrastructure Engineering 2017a, vol. 13 (4), pp. 505-516.

5. Khuc, T.; Catbas, F.N. Completely contactless structural health monitoring of real-life structures using cameras and computer vision. Structural Control and Health Monitoring 2017b, vol. 24, e1852, 13 pages.

6. Zhang, D.; Guo, J.; Lei, X.; Zhu, C. A high-speed vision-based sensor for dynamic vibration analysis using fast motion extraction algorithms. Sensors 2016, vol. 16, 572, 17 pages.

7. Shariati, A.; Schumacher, T.; Ramanna, N. Eulerian-Based Virtual Visual Sensors to Detect Natural Frequencies of Structures. Journal of Civil Structural Health Monitoring 2015, vol. 5(4), pp. 457-468. DOI: 10.1007/s13349-015-0128-5.

8. Schumacher, T.; Shariati, A. Monitoring of structures and mechanical systems using virtual visual sensors for video analysis: fundamental concept and proof of feasibility. Sensors 2013, vol. 13, pp. 16551-16564.

9. Yu, J.; Yan, B.; Meng, X.; Shao, X. Measurement of bridge dynamic responses using network-based real-time kinematic GNSS technique. Journal of Surveying Engineering 2016, vol. 142(3), DOI:10.1061/(ASCE)SU.1943-5428.0000167

10. Ye, X.W.; Dong, C.Z.; Liu, T. A review of machine vision-based structural health monitoring: Methodologies and applications. Journal of Sensors 2016, vol. 2016, ID 7103039, 10 pages. 
11. Tian, L.; Pan, B. Remote bridge deflection measurement using an advanced video deflectometer and actively illuminated led targets. Sensors 2016, vol. 16, 1344, 13 pages.

12. Feng, D.; Feng, M.Q.; Ozer, E.; Fukuda, Y. A vision-based sensor for noncontact structural displacement measurement. Sensors 2015, vol. 15, pp. 16557-16575.

13. Shariati, A.; Schumacher, T. Eulerian-Based Virtual Visual Sensors to Measure Dynamic Displacements of Structures. Structural Control and Health Monitoring 2017, vol. 24(10), DOI: $10.1002 / \mathrm{stc} .1977$.

14. Lee, J.J.; Shinozuka, M. A vision-based system for remote sensing of bridge displacement. NDT\&E International 2006, vol. 39, pp. 425-431.

15. Yoneyama, S.; Ueda, H. Bridge deflection measurement using digital image correlation with camera movement correction. Materials Transactions 2012, vol. 53, pp. 285-290.

16. Zhao, X.; Liu, H.; Yu, Y.; Xu, X.; Hu, W.; Li, M.; Ou, J. Bridge displacement monitoring method based on laser projection-sensing technology. Sensors 2015, vol. 15, pp. 84448463.

17. Feng, D.M.; Feng, M.Q.; Experimental validation of cost-effective vision-based structural health monitoring. Mechanical Systems and Signal Processing 2017, vol. 88, pp. 199-211.

18. Feng D.M., Feng M.Q.; Computer vision for SHM of civil infrastructure: From dynamic response measurement to damage detection - A review. Engineering Structures 2018, vol. 156, pp. 105-117.

19. Wu, L.J.; Casciati, F.; Casciati, S. Dynamic testing of a laboratory model via visionbased sensing. Engineering Structures 2014, vol. 60, p.p. 113-125.

20. Kohut, P.; Holak, K.; Martowicz, A. An uncertainty propagation in developed vision based measurement system aided by numerical and experimental tests. Journal of Theoretical and Applied Mechanics 2012, vol. 50, pp. 1049-1061.

21. Jeong, Y.; Park, D.; Park, K.H. PTZ camera-based displacement sensor system with perspective distortion correction unit for early detection of building destruction. Sensors 2017, vol. 17, pp. 430.

22. Sładek, J.; Ostrowska, K.; Kohut, P.; Holak, K.; Ga ska, A.; Uhl, T. Development of a vision based deflection measurement system and its accuracy assessment. Measurement 2013, vol. 46, pp. 1237-1249. 
23. MATLAB: 2019a, Natick, Massachusetts, The Mathworks, Inc. MATLAB version 9.6.0.1174912 (R2019a) Update 5, 2019.

24. Huang, L-K.; Wang, M-J.J. Image thresholding by minimizing the measures of fuzziness. Pattern Recognition 1995, vol. 28 (1), pp. 41-51.

25. Pan, B.; Qian, K.; Xie, H.; Asundi, A. Two-dimensional digital image correlation for inplane displacement and strain measurement: a review. Measurement Science and Technology 2009, vol. 20 (6), 062001.

26. Pan, B.; Xie, H.; Xu, B.; Dai, F. Performance of sub-pixel registration algorithms in digital image correlation. Measurement Science and Technology 2006, vol. 17 (6), 1615.

27. Quine, B.M.; Tarasyuk, V.; Mebrahtu, H.; Hornsey, R. Determining star-image location: A new sub-pixel interpolation technique to process image centroids. Computer Physics Communications 2007, vol. 177, pp. 700-706.

28. Ding, W.; Gong, D.; Zhang, Y.; He, Y. Centroid estimation based on MSER detection and gaussian mixture model. ICSP2014 Proceedings 2014, pp. 774-779.

29. Guizar-Sicairos, M.; Thurman, S.T.; Fienup, J.R. Efficient subpixel image registration algorithms. Opt. Lett. 33, 156-158 (2008).

30. Artese, S.; Achilli, V. and Zinno, R. Monitoring of Bridges by a Laser Pointer. Dynamic Measurement of Support Rotations and Elastic Line Displacements: Methodology and First Test. Sensors 2018, vol. 18(2), pp. 338 1-16.

31. Park, Y.S.; Agbayani, J.A.; Lee, J.H.; Lee, J.J. Rotational angle measurement of bridge support using image processing techniques. Journal of Sensors 2016, ID 1923934 (9 pages).

32. Artese, G.; Perrelli, M.; Artese, S.; Meduri, S.; Brogno, N. POIS, A Low-Cost Tilt and Position Sensor: Design and First Tests. Sensors 2015, vol. 15, pp. 10806-10824.

33. ASCE. Minimum Design Loads and Associated Criteria for Buildings and Other Structures (ASCE/SEI 7-16). American Society of Civil Engineers 2016.

34. Vicente, M.; González, D.; Mínguez, J. Spanish Patent No. ES 2684134 B2. "SISTEMA Y PROCEDIMIENTO PARA LA MONITORIZACIÓN DE ESTRUCTURAS”, Award Date: Oct. $3^{\text {rd }}, 2019$. 